DIVISION OF THE HUMANITIES AND SOCIAL SCIENCES

CALIFORNIA INSTITUTE OF TECHNOLOGY

PASADENA, CALIFORNIA 91125

THE SWING VOTER'S CURSE IN THE LABORATORY

Marco Battaglini

Princeton University

Rebecca Morton

New York University

Thomas R. Palfrey

California Institute of Technology

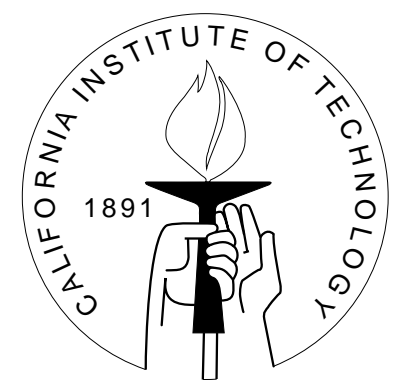

SOCIAL SCIENCE WORKING PAPER 1263

December 2006 


\section{The Swing Voter's Curse in the Laboratory ${ }^{1}$}

\author{
Marco Battaglini² \\ Thomas Palfrey ${ }^{4}$
}

December 5, 2006

${ }^{1}$ This research was supported by the Princeton Laboratory for Experimental Social Science (PLESS). The financial support of the National Science Foundation is gratefully acknowledged by Battaglini (SES-0418150) and Palfrey (SBR-0098400 and SES-0079301). We thank Stephen Coate, participants at the 2006 Wallis Political Economy Conference, and especially Massimo Morelli for comments. Karen Kaiser, Kyle Mattes, and Stephanie Wang provided valuable research assistance.

${ }^{2}$ Department of Economics, Princeton University, Princeton, NJ 08544. Email: mbattagl@princeton.edu

${ }^{3}$ Department of Politics, NYU, 726 Broadway, 7th Floor, New York, NY 10003. Email: rebecca.morton@nyu.edu.

${ }^{4}$ Division of Humanities and Social Sciences, California Institute of Technology, Mail Code 228-77, Pasadena, CA 91125. Email: trp@hss.caltech.edu. 


\begin{abstract}
This paper reports the first laboratory study of the swing voter's curse and provides insights on the larger theoretical and empirical literature on "pivotal voter" models. Our experiment controls for different information levels of voters, as well as the size of the electorate, the distribution of preferences, and other theoretically relevant parameters. The design varies the share of partisan voters and the prior belief about a payoff relevant state of the world. Our results support the equilibrium predictions of the FeddersenPesendorfer model, and clearly reject the notion that voters in the laboratory use naive decision-theoretic strategies. The voters act as if they are aware of the swing voter's curse and adjust their behavior to compensate. While the compensation is not complete and there is some heterogeneity in individual behavior, we find that aggregate outcomes, such as efficiency, turnout, and margin of victory, closely track the theoretical predictions.
\end{abstract}




\section{Introduction}

Voter turnout has traditionally proven to be a difficult phenomenon to explain. Rational models highlight the fact that the incentives to participate in an election depend on the probability of being pivotal. If voting is costly, then significant turnout in large elections is inconsistent with equilibrium behavior. ${ }^{1}$ If voting is costless, then abstention is a dominated choice. However, this is also inconsistent with observed voting behavior. Voters often selectively abstain in the same election-Feddersen and Pesendorfer [1996] report that almost 1 million voters chose to vote in the 1994 Illinois gubernatorial contest but abstained on the state constitutional amendment listed on the same ballot, even though the constitutional amendment was listed first on the ballot. Crain, et al. [1987] report that in the 1982 midterm elections Congressional district turnout levels averaged $3 \%$ higher for the Senate contests in those states with such contests than the House races that were on the same ballot. In seven of the 219 contests they studied the difference in turnout was larger than the margin of victory in the House race, suggesting that voters were abstaining even in close House contests. ${ }^{2}$ Assuming that voting is virtually costless when already in the ballot booth, this would seem to be irrational.

Feddersen and Pesendorfer [1996] show that these large abstention rates can be explained even if the cost of voting is zero if there is asymmetric information, thereby rationalizing such behavior. They draw an analogy between voters' problem and the "winner's curse" observed among bidders in an auction (see Kagel and Levin [2005] and Thaler [1996]). ${ }^{3}$ A poorly informed voter may be better off in equilibrium to leave the decision to the informed voters because his uninformed vote may go against the choice of better informed voters, and could even decide the outcome in the wrong direction. The voter, therefore, may rationally "delegate" the decision to more informed voters by abstaining even if voting is costless. Feddersen and Pesendorfer [1996] name this phenomenon the Swing Voter's Curse.

This theory explains some empirical facts, but it remains-along with rational theories

\footnotetext{
${ }^{1}$ See Ledyard [1984] and Palfrey and Rosenthal [1983, 1985].

${ }^{2}$ They omitted states with gubernatorial contests to focus on the choice whether to vote in both the Senate and House races. Wattenberg, et al. [2000] report that in the 1994 California election $8 \%$ of those who voted for governor abstained in state legislative elections and over $35 \%$ abstained on state supreme court judicial retention votes. They note that the pattern of abstention appears independent of ballot order, with the abstention of those who voted in the governors' race only $2 \%$ on two ballot propositions which were seven ballot positions below the judicial retention elections.

${ }^{3}$ By this term, economists refer to the phenomenon in which bidders in a common value auction overbid with respect to what would be optimal in equilibrium. This occurs because they do not realize that, conditional on winning, the expected value of the object is lower than ex ante. A bidder wins precisely when his or her estimated value of the object for sale is inflated relative to other bidders' estimates, and hence relative to actual value.
} 
of voting more generally-highly controversial. ${ }^{4}$ Empirical evidence has been produced both in favor and against rational voter theories, especially when compared to the assumption that voters act naively and ignore strategic considerations. ${ }^{5} \quad$ None of these results, however, are conclusive, partly because field data sets are not rich enough to identify all the variables that may affect voters' decisions. This is especially true for tests of rational theories of voting based on asymmetric information, such as the Swing Voter's Curse.

This paper reports the first laboratory study of the swing voter's curse. Our results, however, provide insights on the larger "pivotal-voter" literature. This literature includes the earlier models with symmetric information and costly voting (Ledyard [1984], Palfrey and Rosenthal [1983]); asymmetric information and costly voting Palfrey and Rosenthal [1985]); and the broader theoretical literature that focuses on information aggregation in elections with common or private values and asymmetric information (Austen-Smith and Banks [1996], Battaglini [2005], Feddersen and Pesendorfer [1997, 1999] and others).

To overcome the problems with field data, we design a laboratory experiment that provides a sharp test of the theoretical predictions of the Feddersen-Pesendorfer model. The laboratory setting allows us to control and directly observe the level of information of different voters, as well as preferences, voting costs, and other theoretically relevant parameters.

As in Feddersen and Pesendorder [1996], we assume two possible states of the world, $A$ and $B$; and two policies: a status quo and a new proposal. Preferences in the electorate are heterogeneous. There are independent voters who would like to vote for the status quo in state $A$, and for the new proposal in state $B$. There are also partisans who always prefer the status quo regardless of the state. A fraction of the independent voters can be informed on the state of the world, the remaining fraction receives no information. To focus on the incentive to abstain even when voting is costless, we assume a zero cost of voting. The goal of the model is to provide a framework to test the swing voter's curse by studying the behavior of independent voters, and more generally the predictive abilities of informative theories of voting with asymmetric information, heterogeneous level of information and preferences.

To this goal, we consider a two dimensional design which allows us to test the effect of variations in the share of partisan voters and the prior probability of the states on the

\footnotetext{
${ }^{4}$ See Feddersen [2004] for a recent discussion.

${ }^{5}$ Feddersen [2004] reviews this literature. Matsusaka and Palda [1999], based on an extensive study of turnout decisions using both survey and aggregate data, contend that strategic theories of voter turnout provide little explanatory power in explaining voter choices and that turnout decisions appear to be random. Coate, et al. [2006] propose a simple model of expressive voting better, and argue that it explains turnout in local Texas referenda better than the standard pivotal voting model.
} 
voting equilibrium. First we consider the case in which the states are equally likely. In this case, if there are no partisans, the model predicts that all uninformed independents should abstain and "delegate" the choice to informed independent voters. This is a particularly strong form of the swing voter's curse that we have described above which implies zero participation of uniformed voters. As the share of partisans who always vote for the status quo regardless of the state (which for simplicity we call policy $A$, as the state of the world) is increased, the predictions of the model become less extreme: the uniformed independents still abstain with positive probability, but with probability that is decreasing in the share of partisans; moreover when they vote they are expected to vote for the new proposal $(B)$. This result continues to be true even when the state in which the status quo is optimal is more likely: therefore creating a situation in which uninformed independent voters vote against their prior. These predictions of the Nash equilibrium with rational voters, therefore, are in sharp contrast with the prediction of a model of expressive voting, in which voters are not voting on the basis of strategic considerations, but on the basis of the intensity of their preferences as if in a single agent decision problem.

Our empirical results strongly support the prediction of the Nash equilibrium of the model, allowing rejection of the assumption that voters are using naive strategies. Not only are the comparative statics in line with the model, but also the average probability of voting is consistent with the theoretical prediction.

A common prediction in the literature on voting with asymmetric information is that elections tend to aggregate information dispersed among voters. The same phenomenon should be observed in this environment despite the fact that in this model voters do not have common values: though partisans skew the election toward the status quo, the uniformed swing voters endogenously vote to offset this bias. We find significant evidence that uninformed voters do offset the votes of partisans, allowing for information aggregation close to that possible without partisans.

We also find that as the number of voters who are informed increases both turnout and the margin of victory increases, as predicted by the theory. We discuss the implications of the relationship between information, turnout, and victory margins for tests of strategic voting based on field data that focus on the relationship between closeness and turnout levels.

Our attempt to test the pivotal voting model of turnout and behavior using laboratory experiments is significantly different from previous experiments which have primarily focused on cases where information is symmetric and voting is costly. ${ }^{6}$ Much less exper-

\footnotetext{
${ }^{6}$ See Schram and Sonnemans [1996], Cason and Mui [2005], Grosser, et al. [2005] who have studied strategic voters participation in laboratory experiments, focusing on environments with symmetric information and homogeneous costs. One problem with these early works is that, under these assumptions,
} 
imental work has been done with models with asymmetric information. Guarnaschelli, McKelvey, and Palfrey [2000] test Feddersen and Pesendorfer Jury's model (Feddersen and Pesendorfer [1998]) and focus on information aggregation in small committees. They rule out abstention by assumption, and therefore do not provide evidence on participation. Moreover, they assume common values, no partisans, and all voters are equally well informed. Battaglini, Morton, and Palfrey [2005] study sequential voting in a similar model with common values and no partisans. Although they let voters abstain, in their model all voters receive signals of the same quality, so the swing voter's curse can not be observed.

A significant non-experimental empirical literature on turnout exists and a number of these studies attempt to test the pivotal voter model on large elections or a variant of the model as augmented by group and/or ethical motivations for voting. ${ }^{7}$ None of these studies are able to evaluate the role of asymmetric information in explaining abstention and test the swing voter's curse.

A number of researchers have used variations in voter information in field studies to evaluate the effect of information on the choice to abstain which suggest support for the swing voter's curse. ${ }^{8}$ The main finding is that turnout is positively correlated with voter information levels, but this work cannot identify the causal relationship since the demand for political information may be derived from the decision to participate. Recently researchers have examined the impact on turnout of changes in political information where political information is arguably an exogenous variable. McDermott [2005] and Klein and Baum [2001] present evidence that respondents to surveys during elections are more likely to state preferences when information is provided to them. Gentzkow [2005] shows that decreases in voter information associated with the advent to television in U.S. counties is correlated with decreasing voter turnout. Lassen [2005] examined turnout in a Copenhagen election where residents of four of the city's fifteen districts were provided with detailed information about the choices in an upcoming referendum. He finds that voters provided with more information were more likely to participate.

Lassen argues that there are two possible explanations for the relationship between information and turnout-the swing voter's curse theory of Feddersen and Pesendorfer and a decision-theoretic model first suggested by Matsusaka [1995] in which voters are more

voting models may have many equilibria. Levine and Palfrey [2007] have recently conducted expeirments based on a model with heterogeneous costs which has a unique equilibrium. They find support for the three primary predictions of the rational model: (1) turnout declines with the size of the electorate (the size effect); (2) turnout is higher in elections that are expected to be close (the competition effect); and (3) turnout is higher for voters who prefer the less popular alternative (the underdog effect).

${ }^{7}$ See, for example, Hansen, et al. [1987], Filer, et al. [1993], Shachar and Nalebuff [1999], Coate and Conlin [2004], Noury [2004], and Coate, et al. [2006]).

${ }^{8}$ See, for example, Palfrey and Poole [1987], Wattenberg, et al. [2000], and Coupe and Noury [2004]. 
likely to turnout the more confident they are in the correctness of their choices. Gentzkow also notes that his results support a number of theories that argue that information increases turnout including simple decision-theoretic ones as well. Lassen concludes (p. 116): "The natural experiment used here does not allow for distinguishing between the decision-theoretic and game-theoretic approaches ....; this may call for careful laboratory experiments, as the predictions of the models differ in only subtle ways that can be difficult to accomodate in even random social experiments, but the results reported in this article can serve as a necessary first step in motivating the importance of such experiments ..."

The upshot of these studies is that the available natural experiments cannot analyze the data to distinguish between these two approaches and we take the next step in the study of the swing voter's curse in this paper. ${ }^{9}$ In our experimental design we are able to investigate 240 different elections which vary between all voters uninformed to over 70 percent informed. Thus, we can consider the effect of information on aggregate turnout levels as well as the margin of victory, considerations that are difficult to make using natural experiments. As noted above, we are able to consider a variety of degrees of partisan balance and information distribution as well. Finally, we can consider how different individuals choose depending on the information available and the partisan balance. With this wide array of observations we can show that the game theoretic model is a better predictor of behavior than the decision-theoretic approach.

The organization of the reminder of the paper is as follows. In Section I we present the model. Section II characterizes the equilibrium. Section III describes the experimental design and the hypotheses to be tested. Section IV presents the experimental results. Section V concludes. All formal proofs are presented in a technical Appendix at the end of the paper.

\section{The Model}

We consider a game with a set of $N$ voters who deliberate by majority rule. There are two alternatives $A, B$ and two states of the world: in the first state $A$ is optimal and in the second state $B$ is optimal. Without loss of generality, we label $A$ the first state and $B$ the second.

A number $n \leq N$ of the voters are independent voters. These voters have identical preferences represented by a utility function $u(x, \theta)$ that is a function of the state of the

\footnotetext{
${ }^{9}$ Cross sectional and longitudinal studies of electoral behavior, while useful for many purposes, have significant methodological limitations for testing theories of information aggregation and strategic voting. See Groffman [1993].
} 
world $\theta \in\{A, B\}$ and the action $x \in\{A, B\}$ :

$$
\begin{aligned}
& u(A, A)=u(B, B)=1 \\
& u(A, B)=u(B, A)=0
\end{aligned}
$$

State $A$ has a prior probability $\pi \geq \frac{1}{2}$. The true state of the world is unknown, but each voter may receive an informative signal. We assume that signals of different agents are conditionally independent. The signal can take three values $a, b$, and $\phi$ with probability:

$$
\operatorname{Pr}(a \mid A)=\operatorname{Pr}(b \mid B)=p \text { and } \operatorname{Pr}(\phi \mid A)=\operatorname{Pr}(\phi \mid B)=1-p
$$

The agent, therefore, is perfectly informed on the state of the world with probability $p$, and has no information with probability $1-p$.

The remaining $m=N-n$ voters are partisan voters. We assume that the partisans strictly prefer policy $A$ in all states. For convenience we assume that $m$ is even, $n$ is odd and $m \leq n-3 .^{10}$

After swing voters have seen their private signal, all voters vote simultaneously. Each voter can vote for $A$, vote for $B$, or abstain. In any equilibrium, the independent voters who receive an informative signal always strictly prefer the state that matches their signal; and the partisans always strictly prefer state $A$ : in any equilibrium, therefore independents would always vote for the state suggested by their signal, and partisans would always vote for $A$. We can therefore focus on the behavior of the uninformed agents. Let $\sigma_{A}^{i}, \sigma_{B}^{i}$, and $\sigma_{\phi}^{i}$ be respectively the probability that an uninformed agents votes for $A, B$ and abstains.

An equilibrium of this game is symmetric if agents with the same signal use the same strategy: $\sigma^{i}=\sigma$ for all $i$. We analyze symmetric equilibria in which agents do not use weakly dominated strategies and we will refer to them simply as equilibria.

\section{The Voting Equilibrium}

In this section we characterize the equilibria of the voting game, and the equilibrium is unique for the experimental parameters. With respect to Feddersen and Pesendorfer [1996] and other previous results in the literature, we do not limit the analysis to asymptotic results that hold as the size of the electorate grows to infinity, but focus on results that hold even for a finite number of voters. This allows us to test the model directly with an electorate of a size that can be managed in a laboratory. Formal proofs of all the results appear in an Appendix.

\footnotetext{
${ }^{10}$ These assumptions are made only to simplify the notation. In Feddersen and Pesendorfer [1996] $m$ is random variable; however, since they focus the analysis on the limit case in which $n \rightarrow \infty$, the realized fraction of partisan voters is constant by the Law of Large Numbers in their model.
} 


\section{III.1 No Partisan Bias}

We first consider the benchmark case in which all the voters have the same common value, so $m=0$.

Lemma 1 Let $m=0$. If $\pi=\frac{1}{2}$, then $\sigma_{A}=\sigma_{B}$; if $\pi>\frac{1}{2}$, then $\sigma_{A} \geq \sigma_{B}$.

The intuition of this result is as follows. If the uniformed voters are voting for, say $B$, with higher probability, then if pivotal it is more likely that alternative $A$ has attracted more votes from informed voters. If this is the case, then conditioning on the pivotal event, alternative $A$ is more attractive to an uninformed independent, and none of them would vote for $B$, a contradiction.

Though this result provides testable predictions, it can be made more precise:

Proposition 1 Let $m=0$. If $\pi=\frac{1}{2}$, then $\sigma_{A}=\sigma_{B}=0$; if $\pi>\frac{1}{2}$, then $\sigma_{A} \geq \sigma_{B}=0$.

This is a particular form of the Swing Voters' Curse. To see the intuition behind it, suppose the prior is $\pi=\frac{1}{2}$. If an uninformed voter were to choose in isolation, he would be indifferent between the two options $A$ or $B$. When voting in a group, however, he knows that with positive probability some other voter is informed. By voting, he risks voting against this more informed voter. So, since he has the same preferences of this informed voter and he is otherwise indifferent among the alternatives because he has no private information on the state, he always finds it optimal to abstain. When the prior is $\pi>\frac{1}{2}$, the problem of the voter is more complicated. In this case the swing voter's curse is mitigated by the fact that the prior favors one of the two alternatives. As before, the voter does not want to vote against an informed voter. However, he is not sure that there is an informed voter: and if no informed voter is voting, he strictly prefers alternative $A$ since this is ex ante more likely. Thus although the voter never finds it optimal to vote for $B$, he may find it optimal to vote for $A$. The higher is $\pi$, the higher is the incentive to vote for $A$; the higher is $p$ (i.e. the probability that there are other informed voters), the lower is the incentive to vote. For any $p$, if $\pi>\frac{1}{2}$ is not too high, the voter abstains.

From Proposition 1 we know that when $\pi \geq \frac{1}{2}$ a voter would never vote for $B$ if $m=0$, so $\sigma_{B}=0$. Given this, the expected utility of an uninformed voter from voting for $A$, and therefore $\sigma_{A}$, can be easily computed. Let $u_{A}$ and $u_{\phi}$ be respectively the expected utilities of voting for $A$ and abstaining for an uniformed voter, expressed as functions of $\sigma_{A}$. The net utility of voting for $A$ is:

$$
\begin{aligned}
u_{A}-u_{\phi}= & \frac{1}{2}\left[\pi \operatorname{Pr}\left(P_{0} \mid A\right)-(1-\pi) \operatorname{Pr}\left(P_{0} \mid B\right)\right] \\
& +\frac{1}{2}\left[\pi \operatorname{Pr}\left(P_{A} \mid A\right)-(1-\pi) \operatorname{Pr}\left(P_{A} \mid B\right)\right]
\end{aligned}
$$




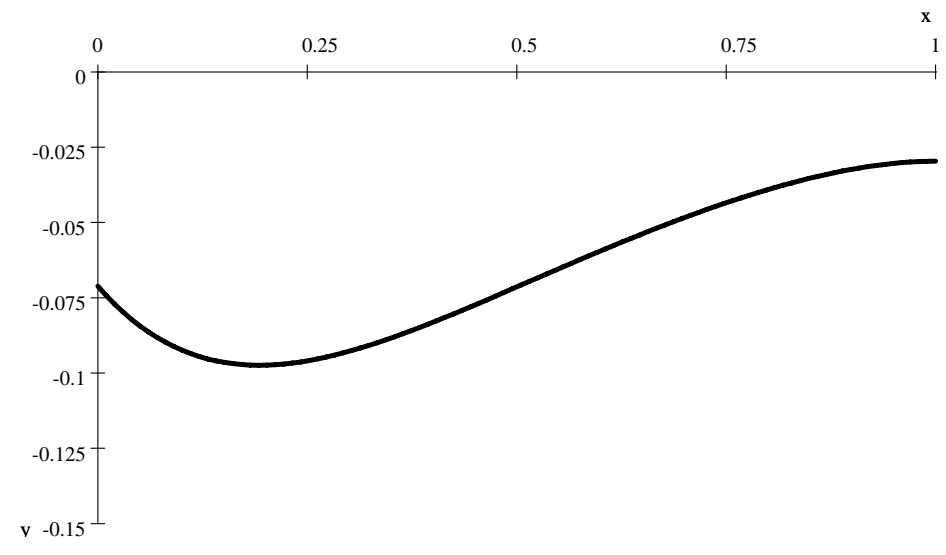

Figure 1: Expected utility of voting for $A$ when $\pi=\frac{5}{9}$ when $m=0$

where

$$
\begin{aligned}
& \pi \operatorname{Pr}\left(P_{0} \mid A\right)-(1-\pi) \operatorname{Pr}\left(P_{0} \mid B\right) \\
= & \pi\left((1-p)\left(1-\sigma_{A}\right)\right)^{n-1} \\
& -(1-\pi) \sum_{j=0}^{\frac{n-1}{2}}\left(\frac{(n-1) !}{\left(\frac{n-1-2 j}{2}\right) !\left(\frac{n-1-2 j}{2}\right) !(2 j) !}\right)\left((1-p)\left(1-\sigma_{A}\right)\right)^{2 j} p^{\frac{n-1-2 j}{2}}\left((1-p) \sigma_{A}\right)^{\frac{n-1-2 j}{2}},
\end{aligned}
$$

and

$$
\begin{aligned}
& \pi \operatorname{Pr}\left(P_{A} \mid A\right)-(1-\pi) \operatorname{Pr}\left(P_{A} \mid B\right) \\
= & -(1-\pi) \sum_{j=0}^{\frac{n-3}{2}}\left(\frac{(n-1) !}{\left(\frac{n-(2 j+1)}{2}\right) !\left(\frac{n-2-(2 j+1)}{2}\right) !(2 j+1) !}\right) \\
& \cdot\left((1-p)\left(1-\sigma_{A}\right)\right)^{(2 j+1)} p^{\frac{n-(2 j+1)}{2}}\left((1-p) \sigma_{A}\right)^{\frac{n-2-(2 j+1)}{2}} .
\end{aligned}
$$

since in this case $\operatorname{Pr}\left(P_{A} \mid A\right)=0$ (in state $A$ no voter ever votes for $B$ ). If uninformed voter mix between voting for $A$ and abstaning in equilibrium, then the equation that gives us $\sigma_{A}$ is: $u_{A}-u_{\phi}=0$. From Proposition 1 we know that $\sigma_{A}=0$ when $\pi=\frac{1}{2}$, so we only need to compute the equation for the case in which $\pi>\frac{1}{2}$. Equation (1) can be easily computed for specific parameters. In Figure 1 we represent the expected utility of voting $A$ for an uninformed voter when the model is parametrized as follows: $p=\frac{1}{4}$, $n=7, m=0$ and $\pi=\frac{5}{9}$. As it can be seen the expected utility of voting for $A$ is always negative for any $\sigma_{A}$ in $[0,1]$, meaning that in the unique equilibrium, we have a corner solution in which the uninformed voters always abstain. 


\section{III.2 Partisan Bias}

Let us now consider an environment in which $A$ has a partisan advantage: $m>0$ Assume first that $\pi=\frac{1}{2}$. In this case the swing voter's curse is confounded by the bias introduced by the partisans. Conditioning on the event in which the two alternatives receive the same number of votes, the voter realizes that it is more likely that $B$ has received some votes from informative voters because he knows for sure that some of the votes cast in favor of $A$, coming from partisans, are uninformative. Indeed, the voter may be willing to vote for $B$, because doing so offsets a partisan vote. As in the previous case with $m=0$, the voters' problem is more complicated when $\pi>\frac{1}{2}$. In this case the prior probability favors $A$, so the incentives to vote for $B$ are weaker, and a voter will find it optimal to do so only if there are enough informed voters in the population. This is summarized in the following result:

Lemma 2 Let $m>0$. If $\pi=\frac{1}{2}$, then $\sigma_{A} \leq \sigma_{B}$; if $\pi>\frac{1}{2}$, then there is a $\bar{p}$ such that $p>\bar{p}$ implies $\sigma_{A} \leq \sigma_{B}$.

In this case too this result can be made more precise by showing that no voter would ever vote for $A$ :

Proposition 2 Let $m>0$. If $\pi=\frac{1}{2}$, or if $\pi>\frac{1}{2}$ and $p$ is large enough, then $\sigma_{B}>\sigma_{A}=0$.

\section{III.3 Comparative Statics}

The probability with which the uninformed voters vote for $B$ depends on the paramethers of the model, $m, p, n, \pi$. For example, the higher is the bias in favor of $A$, the higher is the incentive for uninformed voters to offset it by voting for $B$. The exact probability $\sigma_{B}$ can be easily computed for specific parameter values when $m>0 .{ }^{11}$ From Proposition 1 we know that we only have one variable to determine, $\sigma_{B}$; and one equation to respect: in a mixed strategy equilibrium the agent must be indifferent between abstaining and voting for $B$. This indifference condition requires that the net expected utility of voting to be zero. We can write the equilibrium condition as:

$u_{B}-u_{\phi}=\frac{1}{2}\left[(1-\pi) \operatorname{Pr}\left(P_{0} \mid B\right)-\pi \operatorname{Pr}\left(P_{0} \mid A\right)\right]+\frac{1}{2}\left[(1-\pi) \operatorname{Pr}\left(P_{B} \mid B\right)-\pi \operatorname{Pr}\left(P_{B} \mid A\right)\right]=0$

\footnotetext{
${ }^{11}$ The case with $m=0$ is not necessary since from Proposition 2 we know that the uninformed voters always abstain.
} 


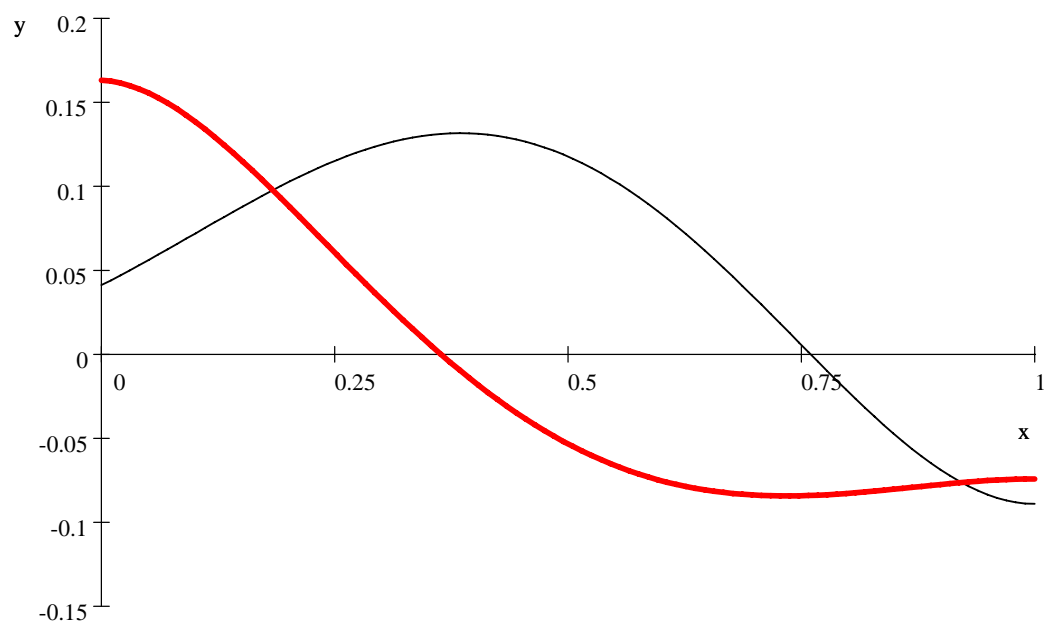

Figure 2: Expected utility of voting for $B$ when $\pi=\frac{1}{2}$ when $m=2$ (thick line) and when $m=4$ (thin line).

where $u_{B}$ is the expected utility of voting for $B$ for an uninformed voter; $(1-\pi) \operatorname{Pr}\left(P_{0} \mid B\right)-$ $\pi \operatorname{Pr}\left(P_{0} \mid A\right)$ is equal to:

$$
\begin{aligned}
& (1-\pi)\left(\frac{(n-1) !}{(n-1-m) ! m !}\right)\left((1-p)\left(1-\sigma_{B}\right)\right)^{n-1-m}\left(p+(1-p) \sigma_{B}\right)^{m} \\
& -\pi \sum_{j=0}^{\frac{n-1-m}{2}}\left(\frac{(n-1) !}{\left(\frac{n-1-2 j-m}{2}\right) !\left(\frac{n-1-2 j+m}{2}\right) !(2 j) !}\right)\left((1-p)\left(1-\sigma_{B}\right)\right)^{2 j} . \\
& \cdot p^{\frac{n-1-2 j-m}{2}}\left((1-p) \sigma_{B}\right)^{\frac{n-1-2 j+m}{2}},
\end{aligned}
$$

and $(1-\pi) \operatorname{Pr}\left(P_{B} \mid B\right)-\pi \operatorname{Pr}\left(P_{B} \mid A\right)$ is equal to:

$$
\begin{aligned}
& (1-\pi)\left(\frac{(n-1) !}{(n-m) !(m-1) !}\right)\left((1-p)\left(1-\sigma_{B}\right)\right)^{n-m}\left(p+(1-p) \sigma_{B}\right)^{m-1} \\
& -\pi \sum_{j=0}^{\frac{n-3-m}{2}}\left(\frac{(n-1) !}{\left(\frac{n-(2 j+1)-m}{2}\right) !\left(\frac{n-2-(2 j+1)+m}{2}\right) !(2 j+1) !}\right) \\
& \cdot\left((1-p)\left(1-\sigma_{B}\right)\right)^{(2 j+1)} p^{\frac{n-(2 j+1)-m}{2}}\left((1-p) \sigma_{B}\right)^{\frac{n-2-(2 j+1)+m}{2}} .
\end{aligned}
$$

In Figure 2 we represent the expected utility of voting for $B$ for an uninformed voter when $p=\frac{1}{4}, n=7, \pi=0.5$. The dark line corresponds to the case with $m=2$, the light line to the case in which $m=4$. As it can be immediately seen, in both cases we have a unique symmetric equilibrium since the expected utility of voting for $B$ intersects the horizontal axis only once in the $[0,1]$ interval. When $m=2$, the equilibrium strategy is 
$\sigma_{B}=0.36 ;$ when $m=4$, we have $\sigma_{B}=0.76 .^{12}$

In a similar way we can find the equilibrium in the case in which $\pi>0.5$. We have explicitly computed the equilibrium when $\pi=\frac{5}{9}$, and the other parameters are as above. In this case too we have a unique equilibrium in correspondence of which with $m=2$, $\sigma_{B}=0.33$, and with $m=4, \sigma_{B}=0.73$. Not surprisingly, a small increase in $\pi$ has a small effect on the equilibrium strategies and tends to reduce the probability of voting for $B$.

Our results then provide testable predictions about voter behavior as a function of $\pi$ and $m$. Later we compare our results to alternative, decision-theoretic, models of turnout as well. That is, if information increases turnout increases simply because voters are more certain about their choices as posited by Matsusaka [1995], then we would not expect uninformed voters to vote for $B$ more often when there is a partisan bias as compared to no bias. In voters vote on the basis of their prior, the change in $\pi$ from .5 to .55 should induce them to vote for $A$, regardless of the partisan bias. ${ }^{13}$

\section{Experimental Design}

We use controlled laboratory experiments to evaluate the theoretical predictions. Once a specific parametrization for $n, m$, and $p$ is chosen, the model described and solved in the previous section can be directly tested in the lab without changes. All the laboratory experiments used $n=7$ and $p=0.25$. We used two different treatments for the state of the world: $\pi=1 / 2$ and $\pi=5 / 9$ and three different treatments for partisan bias: $m=0,2$, and 4 . Table 1 summarizes the equilibrium strategies for each treatment as derived in the previous section.

In the last row of Table 1 we contrast our theoretical predictions with those of the decision theoretic approach of Matsusaka [1995]. Matsusaka assumes that voters participate for consumption benefits that are independent of whether they are pivotal. These consumption benefits are positively related to voters' certainty over which choices yield them the highest utility which depends on their information about the choices. When voters' are uninformed and perceived all options as equally likely, the decision-theoretic model predicts that they will abstain, but that more precise information increases the probability that they will vote.

Thus, in our experimental design, uninformed decision-theoretic voters should abstain when $\pi=0.5$, regardless of the size of the partisan bias. When $\pi=5 / 9$, uninformed decision-theoretic voters should have a positive probability of voting for $A$ and a zero

\footnotetext{
${ }^{12}$ Unless otherwise noted in the paper, we round off to two decimal places.

${ }^{13}$ This is also consistent with models of expressive voting. See, for example, Coate, et al. [2006].
} 
probability of voting for $B$, regardless of the size of the partisan bias.

\begin{tabular}{|c|c|c|}
\hline Table 1: Equilibrium Strategies for Uninformed Voters \\
\hline & \multicolumn{2}{|c|}{ Probability of State $A$} \\
\hline Partisan Bias & $\pi=1 / 2$ & $\pi=5 / 9$ \\
\hline$m=0$ & $\sigma_{B}=\sigma_{A}=0$ & $\sigma_{A}=\sigma_{B}=0$ \\
\hline$m=2$ & $\sigma_{B}=0.36>\sigma_{A}=0$ & $\sigma_{B}=0.33>\sigma_{A}=0$ \\
\hline$m=4$ & $\sigma_{B}=0.76>\sigma_{A}=0$ & $\sigma_{B}=0.73>\sigma_{A}=0$ \\
\hline Decision-Theoretic Voters & $\sigma_{B}=\sigma_{A}=0$ & $\sigma_{A}>\sigma_{B}=0$ \\
\hline
\end{tabular}

The experiments were all conducted at the Princeton Laboratory for Experimental Social Science and used registered students from Princeton University. Four sessions were conducted, each with 14 subjects. ${ }^{14}$ Each subject participated in exactly one session. Each session was divided into three subsession, each of which lasted for 10 periods. All three subsessions used the same value of $\pi$, but used different values of $m=0,2$, and 4 . We varied the sequence of $m$ in the different sessions in order to provide some control for learning effects. Table 2 summarizes the experimental design.

Subjects were randomly divided into groups of seven for each period. Instructions were read aloud and subjects were required to correctly answer all questions on a short comprehension quiz before the experiment was conducted. Subjects were also provided a summary sheet about the rules of the experiment which they could consult. The experiments were conducted via computers. ${ }^{15}$ Subjects were told there were two possible jars, Jar 1 and Jar 2. Jar 1 contained six white balls and two red; jar 2 contained six white balls and two yellow. The monitor from the experiment randomly chose a jar for each group in each period by tossing a fair die according to the value of $\pi$ in the treatment where jar 1 was equivalent to state $A$ in the model and jar 2 was equivalent to state $B$ in the model. ${ }^{16}$ The balls were then shuffled in random order on each subject's computer screen, with the ball colors hidden. Each subject then privately selected one ball by clicking on it with the mouse revealing the color of the ball to that subject only. The subject then chose whether to vote for jar 1, vote for jar 2, or abstain. In the treatments without partisan bias, i.e. $m=0$, if the majority of the votes cast by the group were for the correct jar, each group member, regardless of whether he or she voted, received a payoff of 80 cents. If the majority of the votes cast by the group were incorrect guesses, each group member, regardless of whether he or she voted, received a payoff of 5 cents. Ties

\footnotetext{
${ }^{14}$ Each session included one additional subject who was paid $\$ 20$ to serve as a monitor.

${ }^{15}$ The computer program used was similar to Battaglini, et al. [2005] as an extension to the open source Multistage game software. See http://multistage.ssel.caltech.edu.

${ }^{16}$ We used a 10 sided die with numbers $0-9$ when $\pi=5 / 9$, where numbers $1-5$ resulted in state $A$, numbers 6-9 resulted in state $B$, and if a number 0 was thrown, the die was thrown until 1-9 appeared.
} 
were broken randomly. In the treatment with partisan bias, subjects were told that the computer would cast $m$ votes for jar 1 in each election. This was repeated for 30 periods, with the variations described in Table 2 above, and with the group membership shuffled randomly after each round. Each subject was paid the sum of his or her earnings over all 40 rounds in cash at the end of the experiment. Average earnings were approximately $\$ 20$, plus a $\$ 10$ show-up payment, with each session lasting about 60 minutes.

\section{Experimental Results}

\section{V.1 Aggregate Voter Choices}

\section{V.1.1 Informed Voters}

Of the 1680 voting decisions we observed, in 422 cases (25.1\%) subjects were informed, that is, revealed a red or yellow ball. Across all treatments and sessions, these informed voters chose $100 \%$ as predicted, $100 \%$ of the time if a voter revealed a red ball, he or she voted for jar 1 (state $A$ ) and $100 \%$ of the time if a voter revealed a yellow ball, he or she voted for jar 2 (state $B$ ). We interpret this as indicating that all subjects had a least a basic comprehension of the task.

\section{V.1.2 Uninformed Voters}

Case 1: $\pi=0.5$

Effects of Treatments on Voter Choices Table 2 summarizes the choices of uninformed voters when $\pi=0.5$. In all treatments we find that uninformed voters abstain in large percentages compared to informed voters and these differences are significant.

We find highly significant evidence that the majority of uninformed voters alter their voting choices as predicted by the swing voter's curse theory and contrary to the decisiontheoretic theory. When $m=0$, uninformed voters abstain $91 \%$ of the time, vote for $A$ less than one percent of the time, and vote for $B 8 \%$ of the time. However, with partisan bias, uninformed voters reduce abstention and increase their probability of voting for $B$. The changes are all statistically significant. In the case of $m=4$ the observed voting choices almost perfectly match the equilibium values; in the $m=2$ treatment there is significantly less abstention than predicted by the theory (51\% versus $64 \%$ ). 


\begin{tabular}{|c|c|c|c|c|}
\hline \multicolumn{5}{|c|}{ Table 2: Uninformed Voter Choices, $\pi=1 / 2$} \\
\hline Partisan Bias & \# obs & $A$ Votes & $B$ Votes & Abstain \\
\hline$m=0$ & 217 & 0.00 & 0.08 & 0.91 \\
\hline$m=2$ & 221 & 0.05 & 0.43 & 0.51 \\
\hline$m=4$ & 206 & 0.04 & 0.77 & 0.19 \\
\hline
\end{tabular}

Session, Ordering, and Learning Effects Figure ?? presents the average choices of uninformed voters over time for the two sessions when $\pi=0.5$. First observe that there are sharp changes in behavior immediately following a change in partisan bias. Second, there appear to be some differences between the two sessions, in Session 2 the probability of voting for $B$ in the $m=2$ treatment (periods 11-20) appears higher than the corresponding periods (1-10) in Session 1 (a difference which is statistically significant at the $10 \%$ level, t-statistic $=1.4$, one-tailed test) and the opposite appears to be true in the $m=4$ rounds (a difference which is not significant at acceptable levels, t-statistic $=$ $0.86)$.

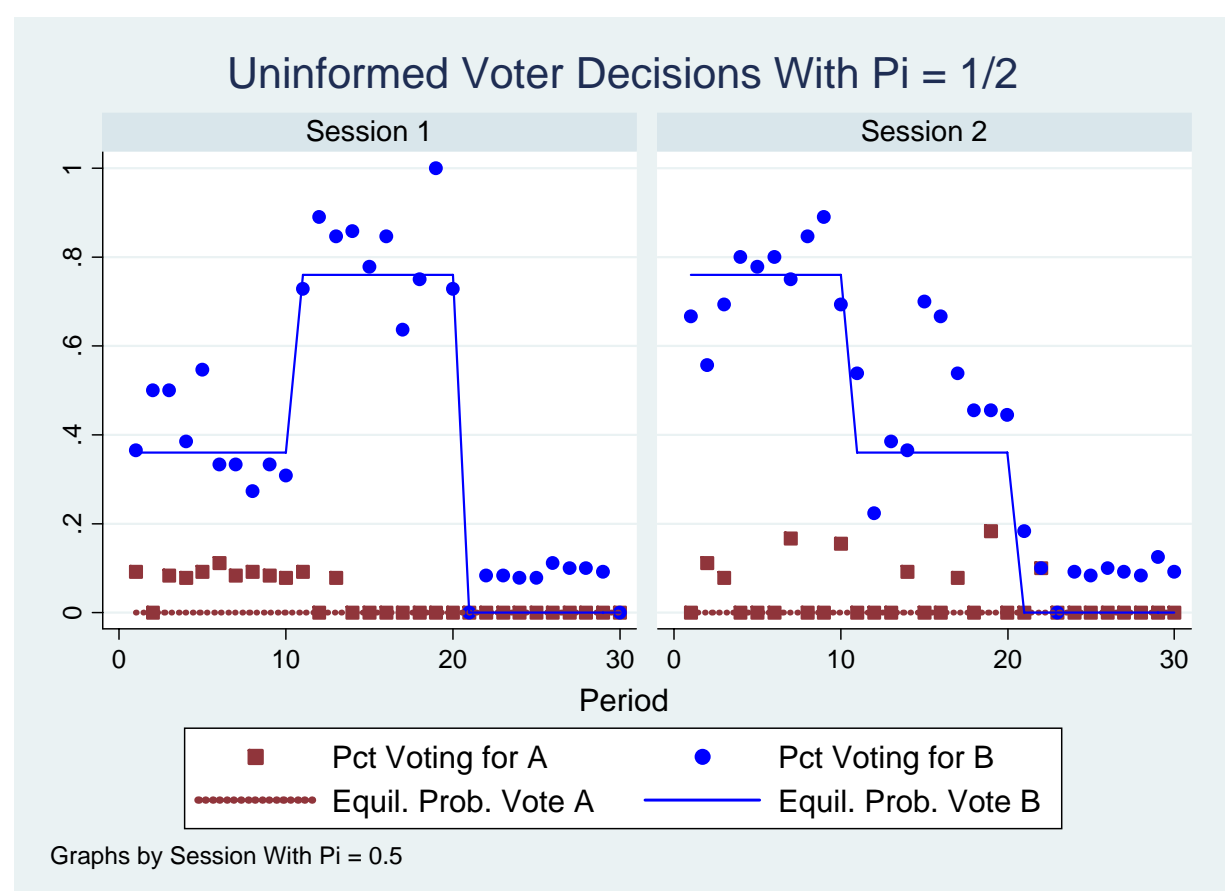

Third, we also tested whether there were significant changes in behavior within a subsession that reflects possible learning. To do this, we estimated separate multinomial probits of voter choices for each subsession as nonlinear functions of the variable period in the subsession (results from these estimations are presented in Appendix, note that 
the standard errors in the estimations were adjusted for clustering by subject). ${ }^{17}$ The estimated probabilities by period are presented in Figure ?? below. As can be seen from the figure, subjects' voting behavior appears to demonstrate learning in early periods in all the subsessions (with some slight increase in nonrational choices towards the end of a subsession) except for the case where $m=2$ when subjects not only vote more for $B$ than the equilibrium level, but increase their voting for $B$ during the early periods in the subsessions with some evidence of learning in later periods in the subsession.

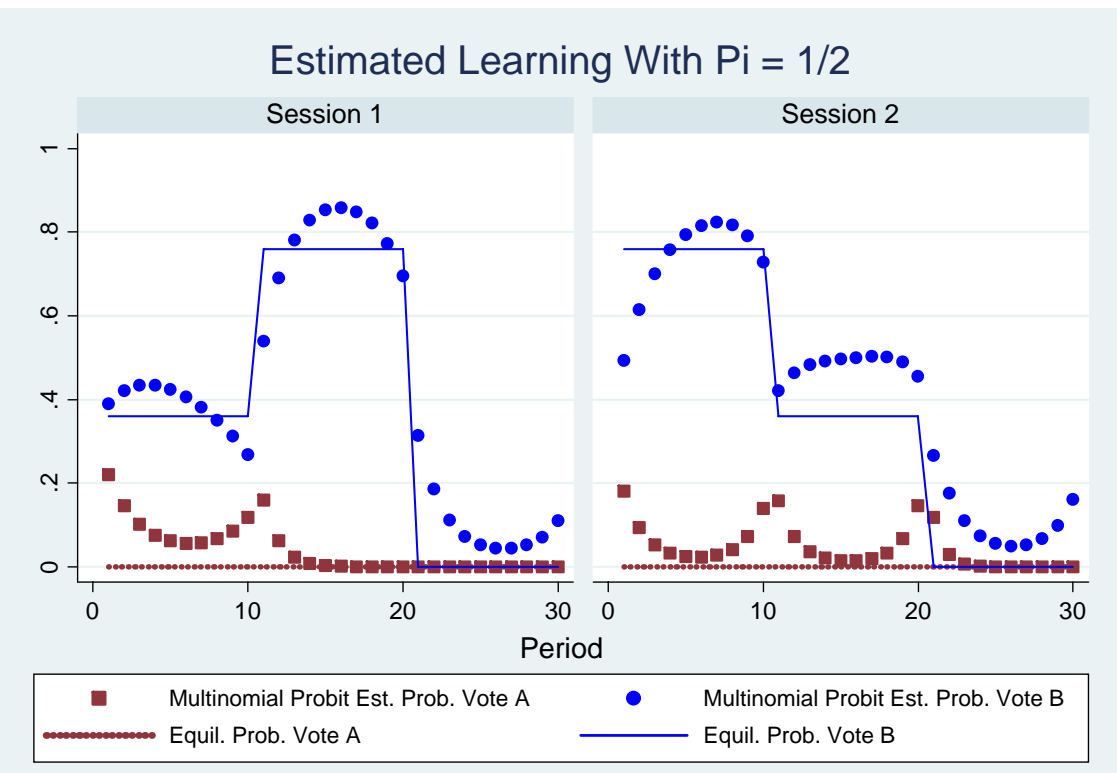

Graphs by Session With $\mathrm{Pi}=0.5$

Case 2: $\pi=5 / 9$

Effects of Treatments on Voter Choices Table 3 summarizes uninformed voter choises when the probability of state $A=5 / 9$. Again, we find that in all treatments uninformed voters abstain large percentages compared to informed voters and these differences are significant, as predicted by the swing voter's curse theory.

\footnotetext{
${ }^{17}$ Multinomial probit or logit is appropriate since the dependent variable is an unordered multinomial response, multinomial logit yielded the same qualitative results. The model was fitted via maximum likelihood in Stata 9. As an alternative to clustering observations by subject, we estimated a fixed effects version of multinomial logit (multinomial probit failed to converge in most subsessions) with largely the same qualitative predictions although in some cases the data was insufficient for accurate predictions. See Wooldridge [2002], pages 496-504 for a discussion of multinomial response models and cluster sampling procedures for their estimation.
} 
We find some support, however, for the decision-theoretic model of voting when $m=0$ as voting for $A$ is significantly higher than when $\pi=0.5$ (19.7\% compared to $0.46 \%)$. But the decision-theoretic model falters as partisan bias increases and we again find highly significant evidence that uninformed voters alter their voting choices as predicted by the swing voter's curse theory and contrary to the decision-theoretic theory. With partisan bias, voting for $A$ when $\pi=5 / 9$ is not significantly different from voting for $A$ when $\pi=0.5$, as predicted by the swing voter's curse theory and contrary to the decisiontheoretic approach. With partisan bias, the percent of uninformed voters voting for $B$ increases with $m$, from $7 \%$ to $30 \%$ to $58 \%$ for $m=0,2,4$, respectively. All of these differences are highly significant.

\begin{tabular}{|c|c|c|c|c|}
\hline \multicolumn{4}{|c|}{ Table 3: Uninformed Voter Choice Frequencies, $\pi=5 / 9$} \\
\hline Partisan Bias & $\#$ obs & $A$ Votes & $B$ Votes & Abstain \\
\hline$m=0$ & & 0.20 & 0.07 & 0.73 \\
\hline$m=2$ & & 0.06 & 0.30 & 0.63 \\
\hline$m=4$ & & 0.04 & 0.58 & 0.38 \\
\hline
\end{tabular}

Session, Ordering, and Learning Effects Figure ?? presents the average choices of uninformed voters over time for the two sessions when $\pi=5 / 9$. First, as in the case where $\pi=0.5$, there are sharp changes in behavior immediately following a change in partisan bias. Second, we also find differences between the two sessions, in Session 3 the probability of voting for $B$ in the treatments with positive partisan bias appear higher than in the same treatments in Session 4. The difference when $m=2$ (periods 21-30 in Session 3 and periods 11-20 in Session 4) is significant at the $10 \%$ level, t-statistic $=1.32$ (one-tailed test) and the difference when $m=4$ (periods 11-20 in Session 3 and periods 21-30 in Session 4) is significant at the $2 \%$ level, t-statistic $=2.07$ (one-tailed test). These differences appear to reflect differences in ordering of the treatments. 


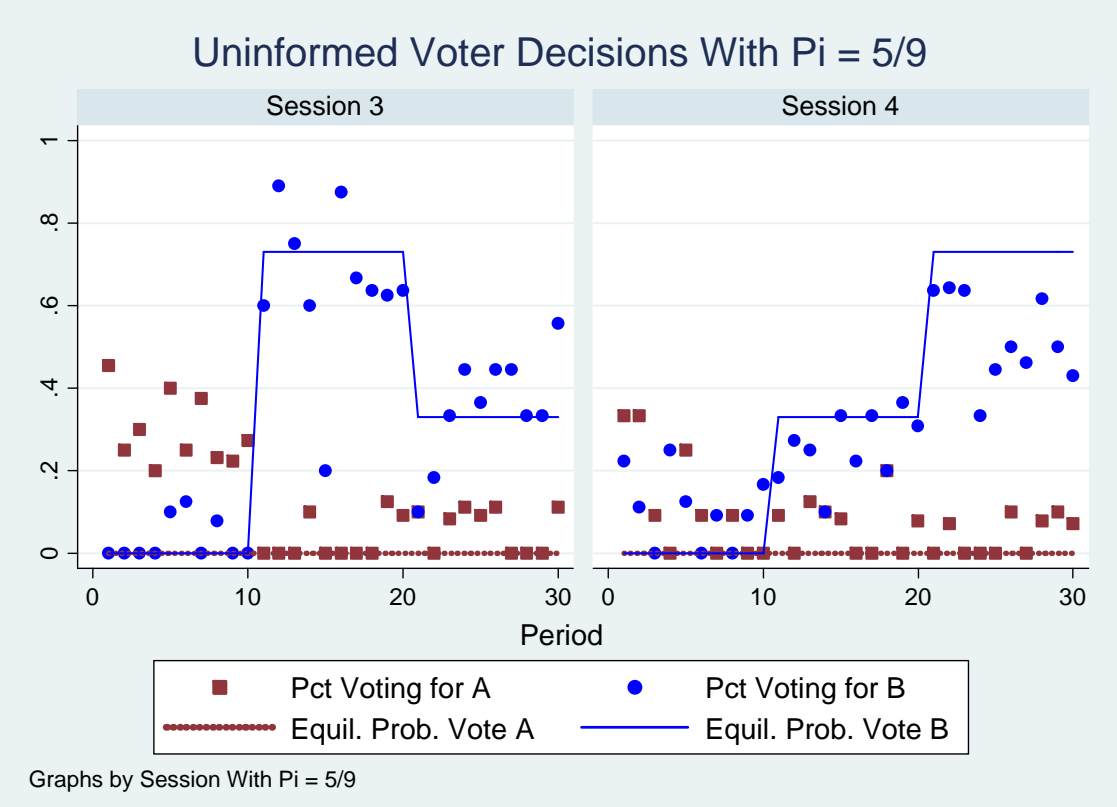

Our analysis suggests that Session 3 voters were primarily responsible for the ability of the decision-theoretic model to explain voting when there is no partisan bias. When $m=0$, (periods 1-10 in both Sessions) uninformed voters in Session 3 cast their ballots for $A 30 \%$ of the time and for $B$ only $3 \%$ of the time, while in Session 4 uninformed voters cast ballots for $A$ exactly same percentage of the time that they cast them for $B$ (10\% of the time). A statistical comparison of voting for $A$ when $m=0$ in Session 3 compared to Session 4 is significant at less than $1 \%$ with a t-statistic $=3.46$.

Third, as for Sessions 1 and 2 we tested whether there were significant changes in behavior within a subsession that reflects possible learning estimating separate multinomial probits for voter choices for each subsession as nonlinear functions of the variable period in the subsession as above (see Appendix for detailed results). The estimated probabilities by period are presented in Figure ?? below. As in the analysis above, we find that learning tends to occur early in subsessions. We find evidence that voter learning trends towards the swing voter's curse theory as compared to the decision-theoretic model; uninformed voters decrease their probability of voting for $A$ as the number of periods in a subsession increases, even in the one case where the decision-theoretic model outperforms the swing-voter's curse (Session 3 when $m=0$ ). 


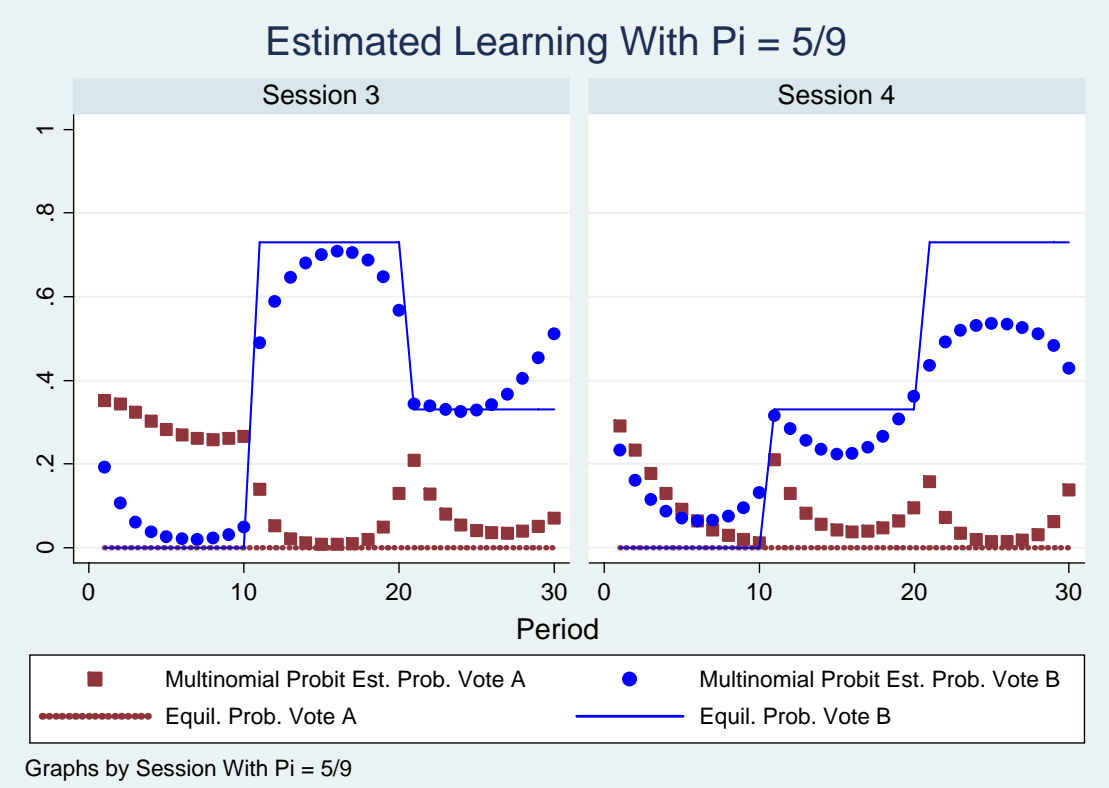

\section{V.1.3 Alternative Models with Bounded Rationality}

So far we have adopted Nash equilibrium behavior as the leading benchmark to explain the data. As discussed above, in our voting environment the predictions of the Nash equilibrium provide a good fit. Can alternative behavioral models provide a similar or better fit? As we said, the data unequivocally reject decision theoretic models that postulate no strategic sophistication. The literature, however, provides a wide range of alternative models of bounded strategic sophistication. It would be impossible to discuss all of them here, so we focus on three approaches that have received particular attention in recent work. First, the so called Level $k$ theories, second the Cursed Equilibrium, finally the Quantal Response Equilibrium.

Bounded rationality I: Strategic Sophistication One recent approach to bounded rationality in games is to relax the assumption that players have perfectly accurate beliefs about how the other players in the game are making their choices. The models proposed by Nagel[], Stahl and Wilson[], and Camerer, Ho, and Chong [2003] posit diversity in the population with respect to levels of strategic sophistication. These "Level- $k$ " models are anchored by the lowest level types, or "Level-0 players", who are completely naive. In the specific context of the swing voter's curse, the obvious way to define level 0 players is that they do not condition on being pivotal, and simply vote their posterior belief of the state, as in the decision theoretic model. Higher types are more sophisticated, but have 
imperfect beliefs about how others will be playing the game. Level-1 players optimize assuming they face a world of level-0 players; level-2 players act as if they face a world of level-1 players; and so forth. In general then, Level- $k$ players optimize assuming they face a world of level- $(k-1)$ players. The number of levels is in principle unbounded. This model was introduced by Stahl and Wilson [] and applied by Crawford and Irriberri [2006] to study the winners' curse in experimental auctions.

It is easy to characterize the predictions of this model in our specific voting environment. Informed voters have a dominant strategy: so, as in the Nash equilibrium and in the data, they always vote for their signal, regardless of their degree of sophistication. The behavior of the uniformed voters would depend on the treatment. Assume first that $m=0$ and $\pi=1 / 2$. A level 0 voter would be indifferent between voting A, B or abstain. Given this, it can be shown that for all $k$, level $k$ uniformed voters would always abstain. ${ }^{18}$ In this case too, therefore, the prediction is in line with the the Nash equilibrium and with the empirical findings. In all the other treatments, however, the predictions of the Level $k$ model sharply diverges from the Nash equilibrium and the data. Assume $m=0$ and $\pi>1 / 2$. In this case uninformed level-0 types would vote for $A$, while level $k$ would vote for $A$ if $A$ if $k$ even and $B$ if $k$ is odd. The intuition is the following: given that all level $k-1$ are voting for the same policy, say $A$, the level $k$ 's would realize that event $B$ is more likely in the pivotal event, since it can occur only if all the informed voters voted $B$, so they would choose to vote for $B$. Independently of the choice of distribution of types, therefore the model would predict zero abstention. The remaining cases are similar. When $m>0$ and $\pi=1 / 2$, type 1 would randomly vote for A,B or abstain with equal probability. Type 1 would vote for $\mathrm{A}$ for the same reason as above: in the pivotal event the bias introduced by the partisans would make even B more likely. Type 2 would then react by always voting A: this because the vote of the uninformed voters over compensates the bias of the partisans. ${ }^{19}$ Types 4 would then vote for B with probability one. ${ }^{20}$ So, in conclusion: even types would vote $B$ and odd types would vote $A$. Finally consider the case $m>0$ and $\pi>1 / 2$. Type 1 votes $\mathrm{A}$, since the prior favors this option. Types 2 then reacts by all voting B. As above, types 3 would then vote A. Again: odd types always vote $\mathrm{A}$ and even types vote $\mathrm{A}$. These predictions can not be reconciled with the data. First it can not explain abstention in the treatment $m>0, \pi>1 / 2$. Second,

\footnotetext{
${ }^{18}$ Since the informed voters vote their signal sincerely, conditional on being pivotal, it would be more likely that a level 1 votes against the vote of an informed voter than in favor, so he would prefer to abstain. Similarly, if level k-1 voters abstain, then the same reasoning is true for level $\mathrm{k}$ voters.

${ }^{19}$ Formally this follows from the fact that the expected utility of voting A minus the expected utility of abstaining is the negative of the expected utility of voting B minus the expected utility of abstaining, and the fact that when all uninformed voters vote $\mathrm{B}$, the formed is negative.

${ }^{20}$ Given our parametrization the equilibrium is in mixed strategies, when all voters vote $B$, then $B$ is a suboptimal choice.
} 
it can not explain the comparative statics in treatment $m>0, \pi=1 / 2$. In the data we observe that abstention is decreasing in $m$. However the model predicts that abstention is constant, since it may depend only on the fraction of level 0 voters. In the light of this evidence, we conclude that the level $\mathrm{k}$ model is not good in predicting voter's behavior and it is dominated by Nash equilibrium.

Cursed Equilibrium. The idea of the cursed equilibrium was introduced by Rabin and Eyster []. It postulates that players correctly anticipate the marginal distribution of the choices (i.e., votes for A, votes for B, and abstentions) of the other players in the game, but make mistakes in updating their beliefs in the pivotal event: specifically, by failing to account for the correlation between the other players' information and their decisions. In our voting environment, the equilibrium logic requires players to understand that informed voters will vote their information, i.e., there is a strong correlation, while in the "cursed" equilibrium, voters would not take this correlation into account when deciding how to vote. This would lead all voters, both informed and uninformed to simply vote their prior (or posterior) belief, and hence the predictions correspond exactly with the decision theoretic model.

There is also a "partially cursed" equilibrium, which makes more subtle predictions about behavior, and is a realistic hybrid of fully cursed and fully rational behavior. In a partially cursed equilibrium, players form beliefs that partially partially takes account of the correlation, so for our game the predictions would generally lie somewhere between the fully rational Nash equilibrium and decision theoretic model. Formally, in an X-cursed equilibrium, the equilibrium strategy is derived based on beliefs that voter vote naively with probability $\mathrm{X}$ and vote according to the equilibrium strategy with probability 1-X. When $\mathrm{X}=0$ ("fully cursed") voters follow the decision theoretic model; when $\mathrm{X}$ is 1 , they play Nash equilibrium model. This is therefore an extension of the Nash equilibrium, and as such can not do worse than it: by adding an additional free parameter $(\mathrm{X})$ this model can therefore fine tune the prediction of the Nash equilibrium.

The predictions of the cursed equilibrium are easy to characterize for the case $m=0$, $\pi=1 / 2$. In this case the informed voters would vote their signal. The uniformed voters would always abstain, regardless of the level of $\mathrm{X}$. So voters would behave in a cursed equilibrium exactly as in a Nash equilibrium. The cases of the remaining treatments are more complicated and depend on the choice of parameters. Consider the case $m=0, \pi>1 / 2$. If $\mathrm{X}$ is high, than the posterior probability that the state is $A$ for an uninformed voter would be larger than $1 / 2$, and the voter would vote for $A$. So if we want to explain abstention, we need to assume $\mathrm{X}$ sufficiently small, which implies a behavior close to a Nash equilibrium. In this particular treatment, however, we observe in the 
data a significant fraction of votes cast for A. The cursed equilibrium may contribute in explaining this phenomenon if we assume that the population is composed by agents with different degrees of cursedness. This indeed may be supported by the individual behavior analysis of Section XX, where we show that a significant fraction of agents is composed of agents who vote A with probability one when $m=0$ and $\pi>1 / 2$. The cases with $m>0$ and $\pi>1 / 2$ are similar: here too the cursed equilibrium may explain why agents vote for A, though this is a much less frequent phenomenon than with $m=0$. Finally consider the case with $m>0$ and $\pi=1 / 2$, here the cursedness of the equilibrium would tend to reduce the incentives to vote fore $B$, so it would skew downward the fraction of votes for $B$. We do not observe this phenomenon in the data: in fact the fraction of votes for $B$ is almost exactly equal to the Nash prediction.

In summary the cursed equilibrium can explain the data with sufficiently low level of cursedness. The bias introduced by X, however, sometimes pushes the model in the wrong direction and performs worse than a simple Nash equilibrium (if we assume that X is positive). By adding an additional degree of discretionality in fitting the data, however, it may contribute in explaining the votes cast for $A$ in treatments with $\pi>1 / 2$ that can not be explained by the Nash equilibrium.

Quantal response Equilibrium. Quantal response equilibrium applies stochastic choice theory to strategic games, and is motivated by the idea that a decision maker may take a suboptimal action, and the probability of doing so is increasing in the expected payoff of the action. Hence, in contrast to both of the models above, it does not assume that players can perfectly optimize, and therefore is not a pure rational choice model. One way to think about quantal response equilibrium is that players try to "estimate" the expected payoff from each strategy and then choose what appears to be the best strategy. The randomness in choice arises because the players make mistakes in the estimation of their payoffs. However it is an equilibrium model, in the sense that one assumes the estimation of payoffs, although subject to error disturbances, is unbiased. That is, on average players have correct beliefs about payoffs. Thus it is a rational expectations equilibrium model, but with stochastic choice rather than deterministic rational choice. ${ }^{21}$ The probability of choosing a strategy is a continuous increasing function of the expected payoff of using that strategy, and strategies with higher payoffs are used with higher probability than strategies with lower payoffs. A quantal response equilibrium is then a fixed point of the quantal response stochastic choice function. In a logit equilibrium, for any two strategies, the stochastic choice function is given by logit function, described below, with free parameter $\lambda$ that indexes responsiveness of choices to payoffs (or the slope of the logit

\footnotetext{
${ }^{21}$ For a general theoretical background see McKelvey and Palfrey (), or Anderson, Goeree and Holt (). For applications to political science, see....
} 
curve). ${ }^{22}$ That is:

$$
\sigma_{i j}=\frac{e^{\lambda U_{i j}}}{\sum_{k \in S_{i}} e^{\lambda U_{i k}}} \quad \text { for all } i, j \in S_{i}
$$

where $\sigma_{i j}$ is the probability $i$ chooses strategy $j$ and $U_{i j}$ is the equilibrium expected payoff to $i$ if they choose decision $j$. These expected payoffs are of course also conditioned on any information that $i$ might have. Note that a higher $\lambda$ reflects a "more precise" response to the payoffs. The extreme cases $\lambda=0$ and $\lambda \rightarrow+\infty$ correspond to the pure noise (completely random behavior) and Nash equilibrium, respectively.

It is straightforward to apply this to the swing voters curse game. The strategies that voters choose stochastically are $A, B$, and $\phi$, and the quantal response equilibrium choice probabilities of uninformed voters for a given value of $\lambda,\left\{\sigma_{A}^{\lambda}, \sigma_{B}^{\lambda}, \sigma_{\phi}^{\lambda}\right\}$ depend on the utility differences $u_{A}-u_{B}, u_{A}-u_{\phi}$, and $u_{B}-u_{\phi}$, expressions for which are derived in the appendix. ${ }^{23}$

We use standard maximum likelihood estimation techniques to estimate a single value of $\lambda$ for the pooled dataset consisting of all observations of uninformed voter decisions in all 6 treatments. The results are given in table 4 .

\begin{tabular}{ccccccccc} 
Treatment & \multicolumn{2}{c}{ QRE Choice Frequencies } & \multicolumn{2}{c}{ Observed Choice Frequenies } & InL & F \\
& $\mathbf{A}$ & $\mathbf{B}$ & $\mathbf{\Phi}$ & $\mathbf{A}$ & $\mathbf{B}$ & $\mathbf{\Phi}$ & & \\
$\mathbf{. 5}, \mathbf{m}=\mathbf{0}$ & 0.09 & 0.09 & 0.83 & 0.00 & 0.08 & 0.91 & -84.24 & 0.91 \\
$\mathbf{. 5 5}, \mathbf{m = 0}$ & 0.11 & 0.08 & 0.82 & 0.20 & 0.07 & 0.73 & -155.59 & 0.90 \\
$\mathbf{. 5}, \mathbf{m = 2}$ & 0.03 & 0.39 & 0.58 & 0.06 & 0.43 & 0.51 & -197.15 & 0.91 \\
$\mathbf{. 5 5}, \mathbf{m}=\mathbf{2}$ & 0.04 & 0.37 & 0.60 & 0.06 & 0.30 & 0.63 & -171.83 & 0.95 \\
$\mathbf{. 5}, \mathbf{m}=\mathbf{4}$ & 0.00 & 0.71 & 0.29 & 0.04 & 0.77 & 0.19 & -149.70 & 0.81 \\
$\mathbf{. 5 5}, \mathbf{m}=\mathbf{4}$ & 0.01 & 0.68 & 0.31 & 0.04 & 0.58 & 0.38 & -178.84 & 0.79
\end{tabular}

Table 4. Quantal Response Equilibrium estimates. $\widehat{\lambda}=42$

The first three columns of the table present the QRE-predicted values of choice frequencies, evaluated at the estimated $\widehat{\lambda}=42$. The next three columns give the observed choice frequencies in our data. Column 7 reports the value of the likelihood function restricted to the observations in the specific treatment. (There are slightly more than 200 observations for each treatment.) The final column displaysa measure of fit that is constructed from the likehood function. Because we are fitting aggregate choice frequencies in this model, the best possible fit we could get would be a "perfect" model that predicted precisely the observed choice frequencies. Call $\bar{L}$ the value of the log likelihood function

\footnotetext{
${ }^{22}$ The free parameter can also be interpreted as the inverse of the variance of the players' estimates of the expected payoffs of different strategies.

${ }^{23}$ With our experimental parameters, the logit equilibria are unique. To simplify the computational problem of numerically finding solutions for the logit equilbrium, we do not model the choices of informed voters as stochastic, and simply assume they always vote their signal (as, in fact, they did).
} 
at this perfect model, and it is given by $\bar{L}=N_{A} \ln f_{A}+N_{B} \ln f_{B}+N_{\phi} \ln f_{\phi}$ where $N_{j}$ is the number of observations of choice $j$ and $f_{j}$ is the relative frequency of choice $j$ in the data. For the opposite benchmark, $\underline{L}$, we use the value of the log likelihood function for the random $(\lambda=0)$ model, so $\underline{L}=\left(N_{A}+N_{B}+N_{\phi}\right) \ln \left(\frac{1}{3}\right)$. Denoting by $L(\widehat{\lambda})$ the value of the likelihood function at $\widehat{\lambda}=42$, we define our measure of fit as $\frac{L(\widehat{\lambda})-\underline{L}}{\bar{L}-\underline{L}}$. This measure of fit equals 1 for the "perfect" model and equals 0 at the random model, so it measure the improvement over the random model, relative to a perfect model. The fit by this measure is .90 or higher in 4 of 6 treatments, and is lowest in the two $\mathrm{m}=4$ treatments. Another way to understand how well the data is being fitted by the QRE model is to see that the model does not systematically over- or under- predict the choices of different strategies. A scatter diagram of the QRE-predicted frequencies and the observed choice frequencies is shown in figure XX. The observed and predicted values are very close: the regression line through this collection of points has a slope equal to 0.97 , an intercept of 0.01 , and $R^{2}>0.95$.

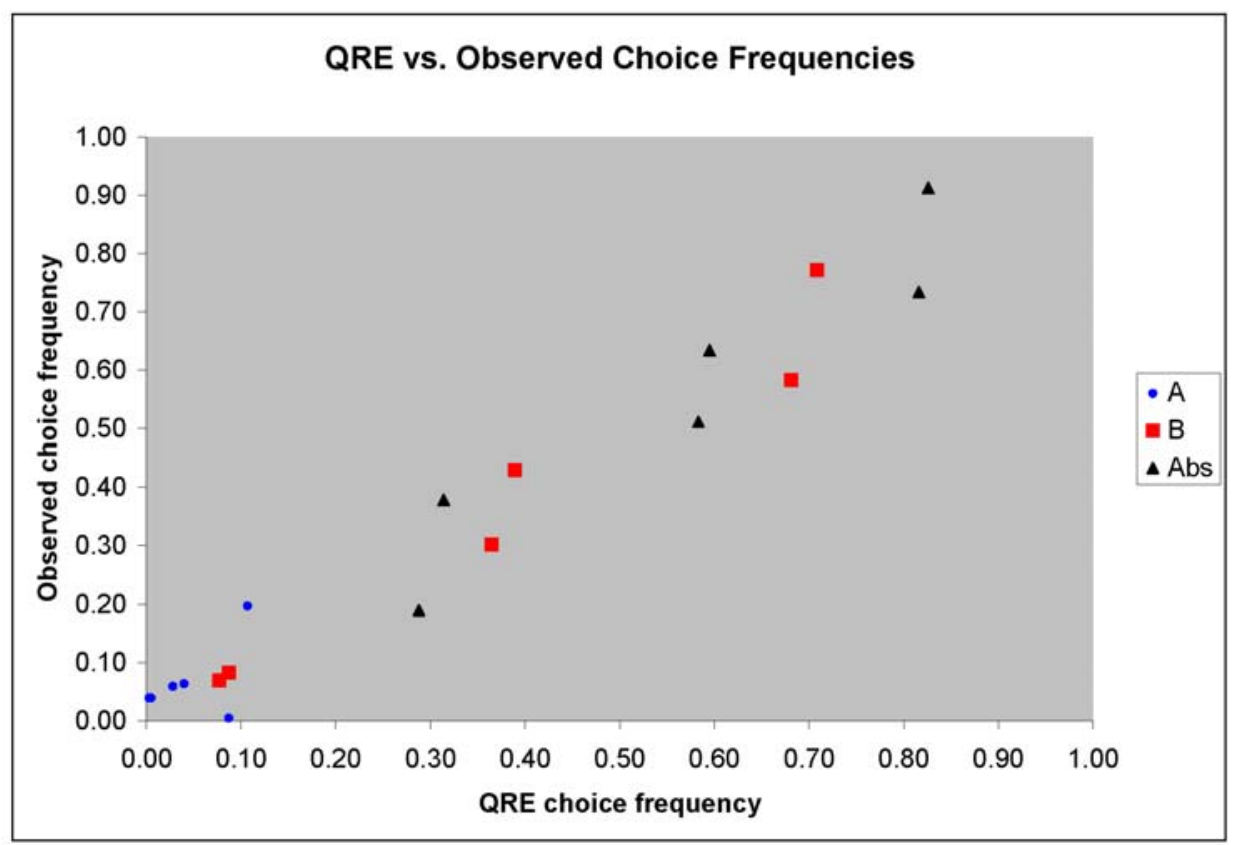

Figure XX. Comparison of observed choice frequencies and QRE-predicted frequencies.

An interesting feature of the data, which is captured in the QRE model is that the 
probability an uninformed voter chooses $A$ is higher when $\pi=.55$ than when $\pi=.50$, and this relationship holds for all values of $\lambda$. This is quite intuitive, because the naive strategy of voting with your prior is obviously not as bad if the prior is further from $1 / 2$, since, a priori, by doing so you will vote correctly more often than not. Of course it is still not optimal because of the pivot calculations and the swing voter's curse, but a $\pi$ becomes further from .5 , the swing voter's curse diminshes. However, this effect is predicted to be very small when $m>0$. In our data, we do find a significant difference in the expected direction for $m=0$, and there is no significant difference for $m>0$.

The QRE probability an uninformed voter votes for $A$ is also a decreasing function of $m$ for all values of $\lambda$. In other words, regardless of the exact value of the QRE noise parameter, the model predicts that $f_{A}$ should be highest when $m=0$ and lowest when $m=4$, which is borne out by our data. The logic behind this is quite intuitive. If $m>0$ then voting for $A$ is a bad strategy not only because it increases the probability that the uninformed voter himself is pivotal (the swing voter's curse), but also because it increases the probability a partisan is pivotal. When $m=0$, there is only the first effect.

\section{V.2 Committee Decisions}

\section{V.2.1 Information and Turnout}

In the previous subsection we averaged across all committees within a treatment. We now turn to an analysis of committee decisions. First we examine therelationship between turnout and the number of informed voters. Theoretically, we expect that as the number of informed voters increases, the turnout level will increase from $\sigma_{B}$ to 1 . That is, in equilibrium informed voters vote $100 \%$ of the time, while uninformed voters cast votes with probability $\sigma_{B}$. When a voter becomes informed then total turnout increases by 1 and decreases by only $\sigma_{B}$.

To evaluate this prediction we estimate the effect of increasing the number of informed voters in a group on the number of voters in the group who chose to vote (including both informed and uninformed voters but excluding of course computer voters). We take our individual voter predictions from the multinomial probit estimations described above and summarized in the Appendix for each voter in each committee in each period in each session to construct a mean committee turnout level by number of informed voters for each subsession. This allows us to estimate the relationship between the number of informed voters and committee turnout levels incorporating individual subject and learning effects that might affect committee turnout levels. ${ }^{24}$

\footnotetext{
${ }^{24}$ We also estimated separate binomial regressions, as described in Wooldridge [2002] pages 659-660, to estimate votes for $A$ and for $B$, which we then used to construct estimated turnout levels by number
} 
Figure ?? presents a comparison of the estimated turnout levels with the actual mean turnout levels of the committees and the swing voter's curse theoretically predicted turnout levels as a function of the number of informed voters. These relationships are only shown for the range of informed voters realized in the subsession-in some subsessions there were no committees with more than 3 informed voters. First notice that although the estimated relationships are nonlinear, reflecting the effects of learning and subject cohorts, the estimated relationships' slopes closely track the theoretical slopes. Thus, even with such effects, our comparative static prediction of the relationship between number of informed voters and committee turnout receives support. Furthermore, as partisan bias increases, the relationship between turnout and number of informed voters becomes flatter as expected.

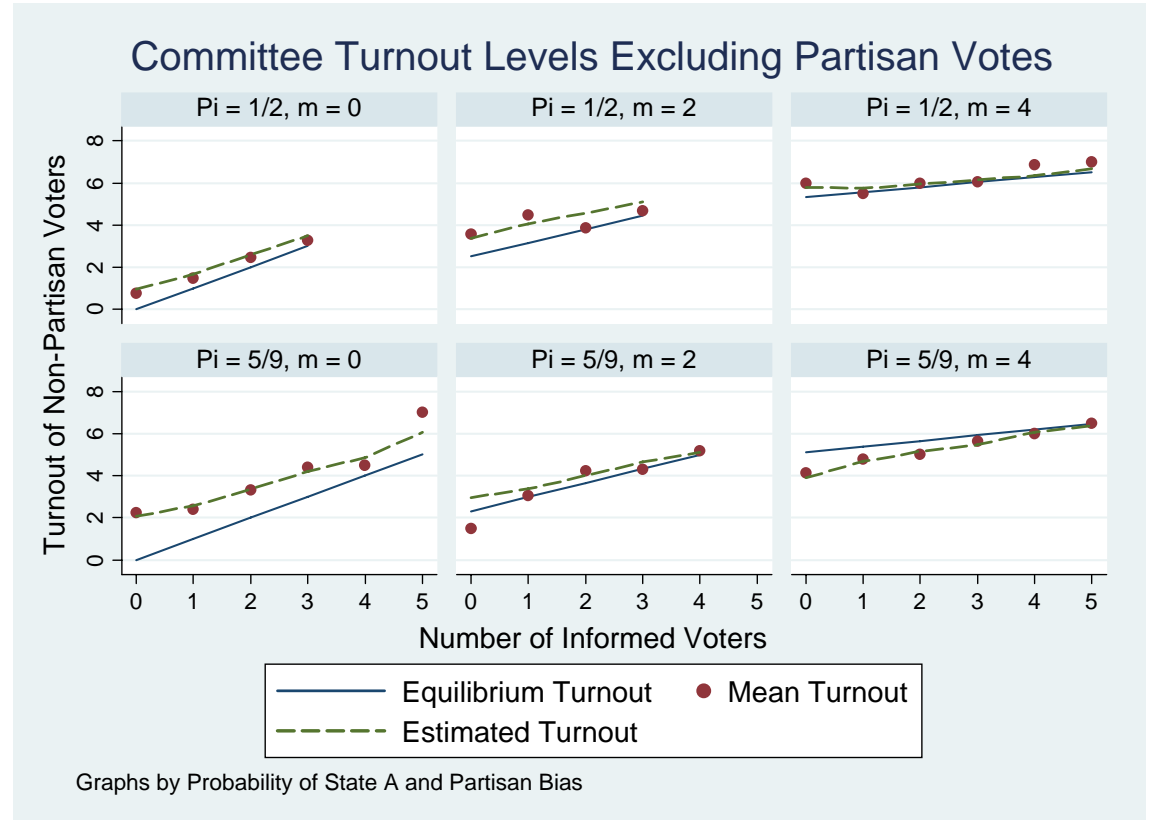

Second, except for the case when $m=4$ and $\pi=5 / 9$, estimated actual turnout exceeds equilibrium turnout, reflecting the tendency of uninformed voters to vote more than predicted when there is zero partisan bias or low levels of partisan bias. When $m=4$ and $\pi=0.5$ the estimated turnout relationships almost perfectly coincide with the equilibrium relationship. These results are consistent with the aggregate individual behavior results reported above; when partisan bias is low, uninformed voters tend to

of informed voters for each subsession. These levels were similar to the ones reported here, but assume an independence between the votes for $A$ and $B$. We also estimated a binomial regression where the dependent variable was aggregate turnout with similar results. Using the multinomial probit estimations allow us to consider subject specific effects and learning that might affect committee turnout choices. 
vote more than predicted, but when partisan bias is high, uninformed voters vote either less or very close to the equilibrium predicted levels.

\section{V.2.2 Margin of Victory and Information}

As the number of informed voters in a committee is expected to affect turnout, it is also expected to affect the margin of victory for the winning outcome. We also evaluate this comparative static prediction by comparing estimated committee margins of victory calculated using the estimated individual probabilities of voting by subject, period, and subsession with the equilibrium probabilties. However, the theoretically predicted margin of victory depends on the signals received by informed voters and thus the true state. For example, if the true state is $A$ and the number of informed voters are $4, m=4$, and $\pi=0.5$, theoretically we expect a victory margin of $|8-3(0.78)|=5.66$ while if the true state is $B$ theoretically we expect a victory margin of $|4-3(0.78)-4|=2.34$. Thus we make two comparisons, we compare the estimated plurality for $A$ with the equilibrium plurality for $A$ when the true state is $A$ and we compare the estimated plurality for $B$ with the equilibrium plurality for $B$ when the true state is $B$. Figures ?? and ?? present these comparisons.

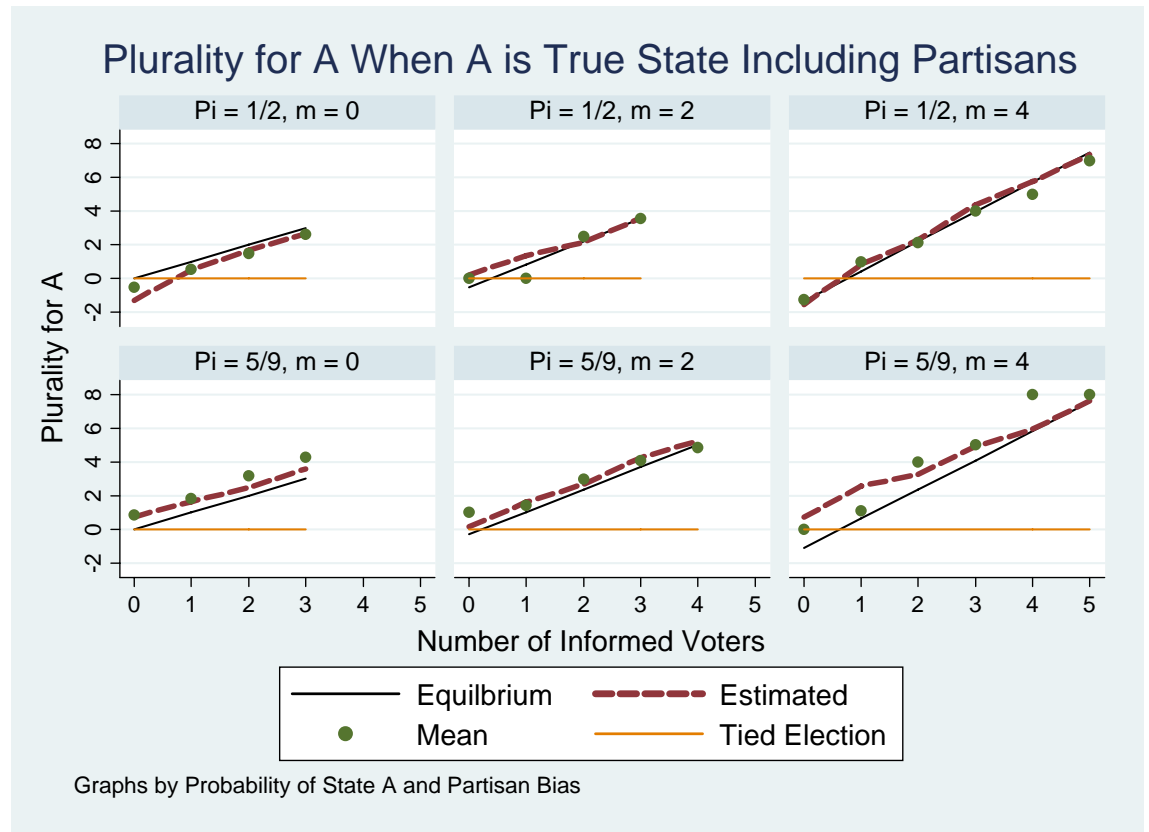




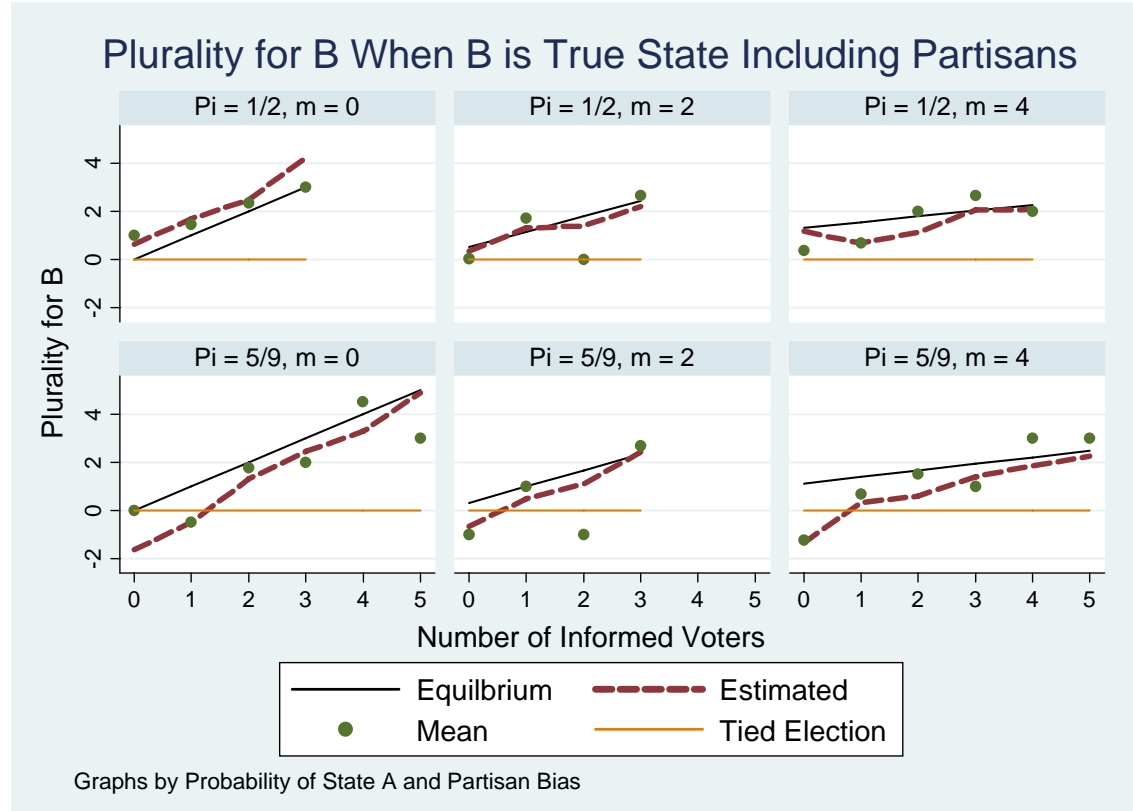

In the figures, the light solid line represents when an election was tied. Observations below this line represent wins by state $B$ and above the line represent wins by state $A$ in Figure ?? and vice-versa in Figure ??. Thus, observations below this line represent cases where committees chose incorrectly, while observations above this line represent cases where committees chose correctly.

First notice that as with the turnout levels, the slope of the equilibrium plurality relationships depend on the degree of partisan bias and the estimated relationships demonstrate similar dependence. Second, we find that generally the margins of victory for $A$ are greater than equilibrium when $A$ is the true state and the margins of victory for $B$ are less than equilibrium when $B$ is the true state, which follows from the excess voting for $A$. Third we find that it takes very few informed voters for the true state to have a positive margin of victory-in most cases with just one informed voter, the plurality of votes in favor of the true state is positive, even when $m=4$. Thus, uninformed voters sufficiently balance out the partisan bias such that the true state receives a positive plurality.

\section{V.2.3 Closeness and Turnout}

A common perceived prediction of the rational model of voting is that turnout should be positively related to the expected closeness of an election since when elections are expected to be close, votes are more likely to be pivotal, and thus the investment benefits from 
voting are greater. ${ }^{25}$ However, in our analysis closeness and turnout may be negatively related since increasing the number of informed voters increases the margin of victory (decreasing closeness) while it increases turnout. These results imply that simple tests of the effect of closeness on turnout decisions or aggregate turnout are not nuanced enough to determine if voters are making participation decisions rationally.

\section{V.2.4 Efficiency of Committee Choices}

Figure ?? below shows the percentage of correct committee choices as a function of the number of informed voters when $\pi=0.5$ (Note that we omit cases where we have no observations, for example, we have no observations when $m<4$ and the number of informed voters is greater than 3). We compare these percentages to the percentages theoretically predicted to be correct which are calculated by estimating the binomial probabilities that a group is correct given the assumed number of informed voters. We find that group decisions are generally either more likely to be correct than theoretically predicted or close to the theoretical prediction. The largest and only statistically significant shortfall occurs when only one voter is informed and $m=0$, theory predicts that the group decision will be correct $100 \%$ of the time, we find that the group decisions are correct only $87.5 \%$ of the time, which is significant at a $2 \%$ confidence level. In some cases, due to fortunate draws, the group decisions are correct a greater percentage of time than theoretically predicted. For example, when $m=0$ and no voter is informed, we predict that the group will be correct $50 \%$ of the time, we find in the experiment that the group is correct $62.5 \%$ of the time. None of these differences are statistically significant, however.

Figure ?? shows the same efficiency comparisons for the case when $\pi=5 / 9$. We find when zero voters are informed, and groups decisions are much lower, however, only for the case where $m=4$ is the difference between the theoretically predicted percent correct and the actual percent correct significantly different at an $8 \%$ confidence level. We also find a significant shortfall in percent correct when only one voter is informed and there is zero partisan bias; only $75 \%$ of the group decisions are correct, although theory predicts that $100 \%$ will be, which is significant at the $2 \%$ confidence level. This reflects the tendency of voters to vote for $A$ when there is zero partisan bias and $\pi>0.5$. However, for the cases where two or more voters are informed, the group is correct $100 \%$ of the time when there is zero partisan bias. There are no other significant differences between the percent of time the group is correct and the theoretical predictions.

In order to evaluate the efficiency of committee decisions we compared the equilibrium probabilities that a committee will make a correct decision for each treatment with the

\footnotetext{
${ }^{25}$ See for example Filer, et al. [1993].
} 


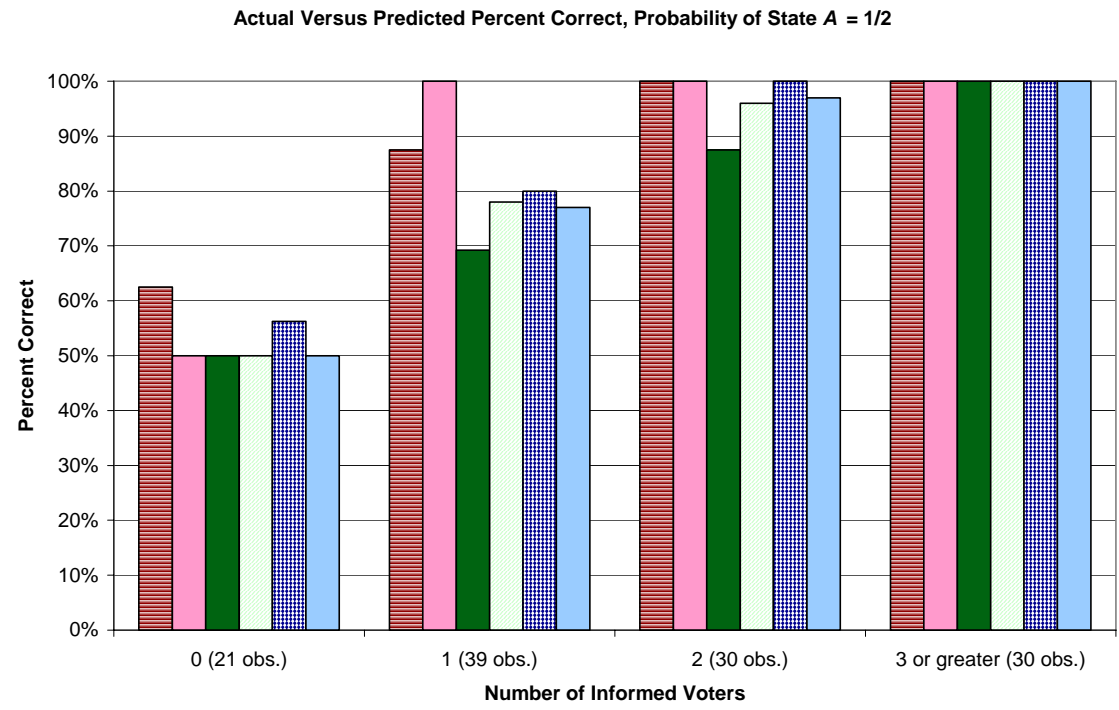

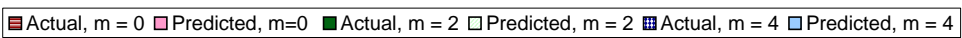

Figure 3:

Actual Versus Predicted Correct, Probability of State $A=5 / 9$

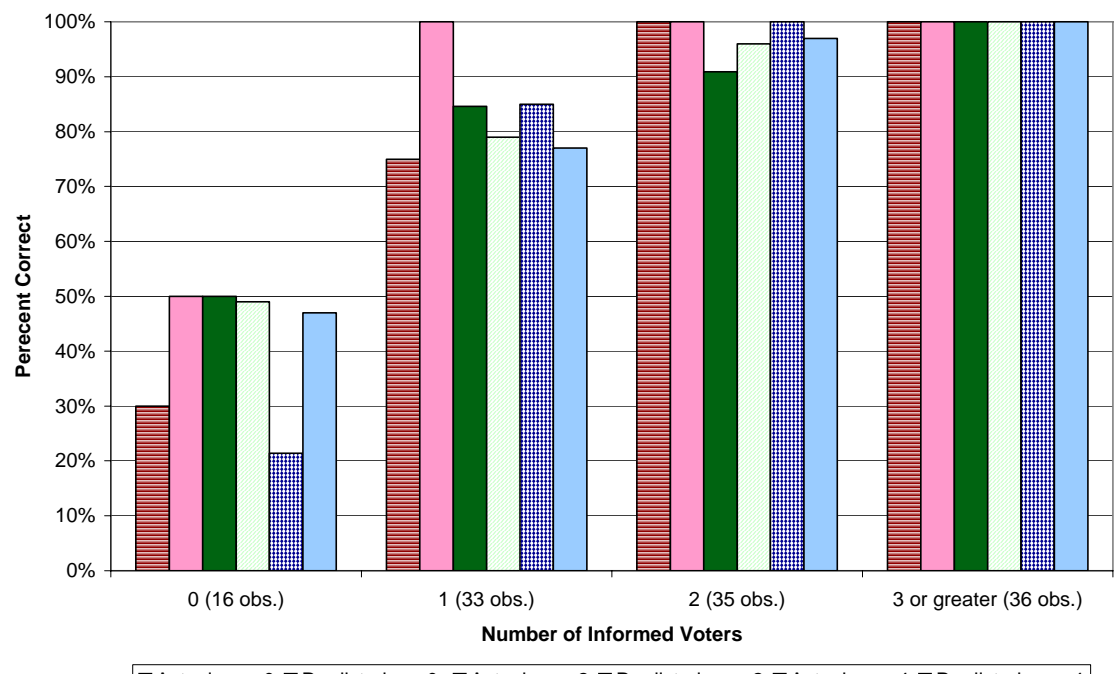

目 Actual, $m=0$ 口Predicted, $m=0$ 口Actual, $m=2$ 口Predicted, $m=2$ 国Actual, $m=4$ 口Predicted, $m=4$

Figure 4: 
estimated probabilities calculated using the probabilities of voting for A, B, or abstaining as estimated by period, group, and treatment in the multinomial probits discussed above. This is shown in figures ??-??.
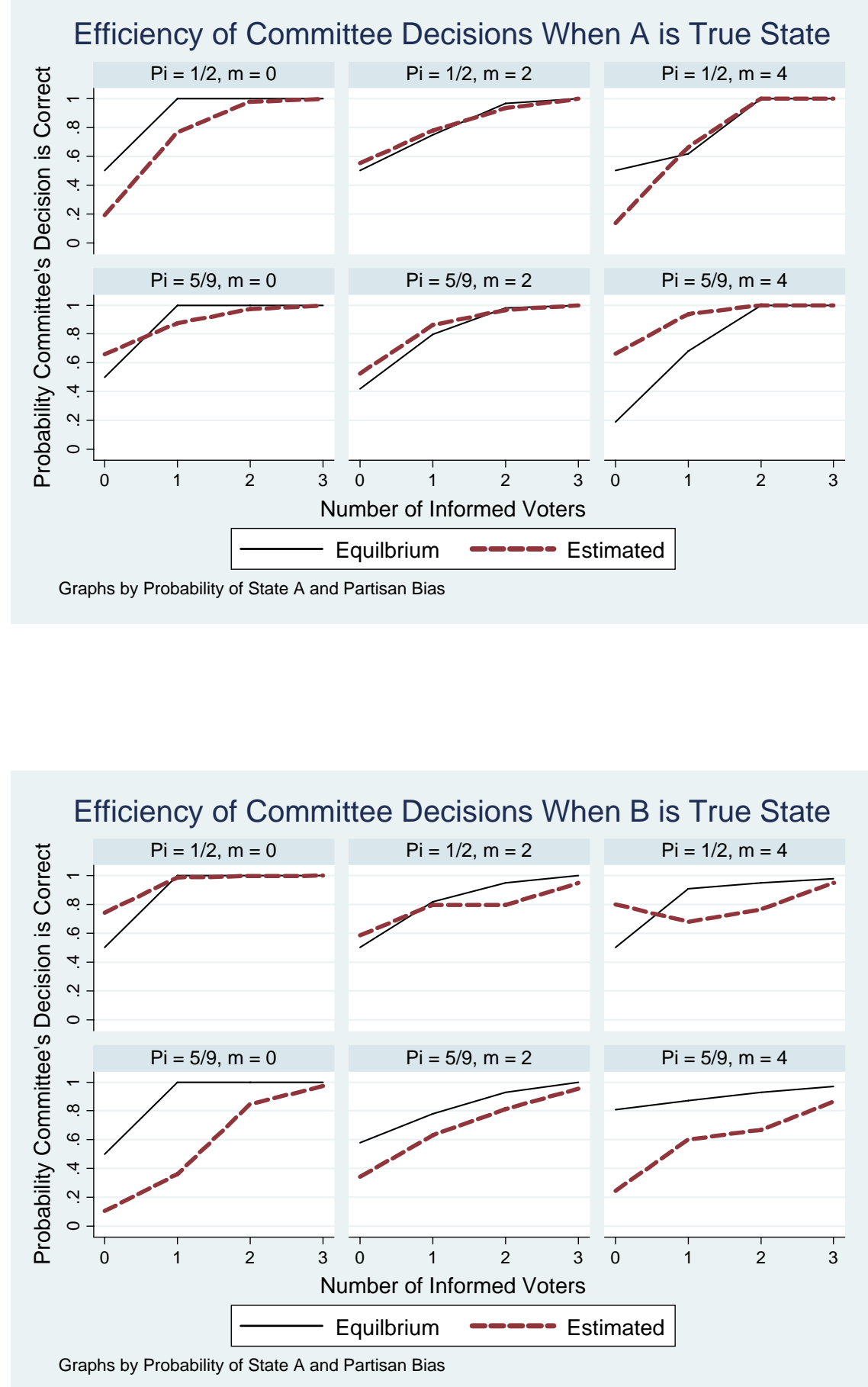
We control for the true state and the number of informed voters since informed voters voted their signals $100 \%$ of the time. For example, consider a committee where $m=0$, $\mathrm{A}$ is the true state, $\pi=0.5$, and there are seven uninformed voters. In this case, we only need to compute the probability that the number of votes received by $A$ is greater than the number of votes received by $B$. We do so by calculating the probability of this event given the estimated individual probabilities of voting for $A, B$, or abstaining from the multinomial probits for this committee which depended on the session and the period of the experiment. Similarly, in a committee where $m=4, B$ is the true state, $\pi=0.5$, and there are five uninformed voters, we need to compute the probability that the number of uninformed voters for $B$ exceeds the number of uninformed voters for $A$ by more than 2 (since $A$ will get 4 computer votes and the 2 informed voters will vote for $B$ ). We performed these calculations for each committee and the particular configuration of computer votes, true state, and number of informed voters.

We find that the committees tend to be less efficient in decision making when $\pi=5 / 9$ and/or the true state is $B$. However, the committee decisions, like the equilibrium decisions, are approximately $100 \%$ correct if there are 3 or more informed voters, even when there are four computer voters and the true state is $B$. Thus, balancing by uninformed voters does help the committees reach more informed decisions than would be reached if uninformed voters voted naively as predicted by the decision-theoretic model.

\section{V.3 Individual Behavior}

In this subsection we analyze patterns of individual behavior. The within subject design enables us to compare how an individual behaves across different treatments; that is, as a function of the number of partisans. For each value of $m$ we classify the subject's behavior as either always abstaining (Abs.), always voting for $B$, or mixing (Abs/B), by observing their choices when uninformed. Individual subject choices are classified by profile in Table 5 below. We classify a subject as following a profile if $90 \%$ or more of his or her choices are predicted choices. Some subjects could not be classified primarily because they frequently either voted when $m=0$ or for $A$ when $m>0$. 


\begin{tabular}{|c|c|c|c|c|c|c|}
\hline \multicolumn{7}{|c|}{ Table 5: Uninformed Voter Individual Profiles } \\
\hline \multicolumn{3}{|c|}{ Partisan Bias } & \multicolumn{4}{|c|}{ Session } \\
\hline$m=0$ & $m=2$ & $m=3$ & 1 & 2 & 3 & 4 \\
\hline Abs. & Abs. & Abs. & 0.07 & 0.07 & 0.07 & 0.14 \\
\hline Abs. & Abs. & $A b s / B$ & & & & 0.14 \\
\hline Abs. & Abs. & $B$ & 0.29 & 0.14 & & 0.07 \\
\hline Abs. & $B$ & $B$ & 0.29 & 0.14 & & \\
\hline Abs. & $A b s / B$ & $B$ & 0.07 & 0.29 & 0.29 & 0.07 \\
\hline Abs. & $A b s / B$ & $A b s / B+$ & 0.07 & 0.07 & 0.14 & 0.21 \\
\hline Abs. & $A b s / B$ & $A b s / B-$ & 0.14 & 0.07 & & \\
\hline \multicolumn{3}{|c|}{ Total } & 0.93 & 0.79 & 0.50 & 0.65 \\
\hline
\end{tabular}

Turning to the subjects who are not classified in Table 5 , when $\pi=5 / 9$ we observed several voters choosing to vote $A$ when $m=0$, particularly in Session 3. We find that a number of voters chose a profile where they voted for $A$ when $m=0$ but either abstained or voted for $B$ when $m>0$. These percentages of subjects choosing these profiles are summarized in Table 6 below with $36 \%$ choosing this type of profile in Session 3 and $14 \%$ in Session 4.

\begin{tabular}{|c|c|c|c|c|}
\hline \multicolumn{4}{|c|}{ Table 6: Additional Profiles } \\
\hline \multicolumn{3}{|c|}{ Partisan Bias } & \multicolumn{2}{c|}{ Session } \\
\hline$m=0$ & $m=2$ & $m=4$ & 3 & 4 \\
\hline$A$ & $A b s$. & $B$ & 0.07 & \\
\hline$A$ & $A b s$. & $A b s$. & 0.14 & \\
\hline Abs $/ A$ & $B$ & $B$ & 0.07 & \\
\hline Abs/A & $A b s / B$ & $B$ & 0.07 & \\
\hline Abs/A & $A b s$. & $A b s$. & & 0.14 \\
\hline Total & & & 0.36 & 0.14 \\
\hline
\end{tabular}

\section{Concluding Remarks}

Significant evidence exists that voters often choose to abstain when voting is apparently costless and the standard rational model of voting would predict participation. Empirical analysis suggests that such abstention may be related to differences in voter information. The Swing Voter's Curse theory provides a complicated game theoretic explanation for why uninformed voters would be willing to abstain and delegate decision making to more informed voters. Hence, it is a candidate explanation for the empirical evidence that lower information elections have lower turnout. In this paper we have provided the first experimental test of the theory, where we control for key parameters of the model, which are difficult to measure precisely or control for in naturally occuring data. We find 
strong support for the theory. Uninformed voters behave strategically: they strategically abstain when uninformed and both outcomes are equally likely, delegating their votes to more informed voters. With partisan bias, they vote strategically to balance out the votes of partisans, at probabilities close to equilibrium, increasing the probability of voting as partisan bias increases. Even when the partisan-favored outcome is the more likely outcome we find most voters balancing in this way. These results are supported at both the aggregate and individual level and across sessions and treatment configurations.

We also find that turnout and margin of victory both increase with the number of informed voters and that there is a positive relationship between these two variables, contrary to the common view that rational models of turnout predict that closeness and turnout should be positively related. These results suggest that tests using field data of whether turnout is related to closeness, which are unable to control for information asymmetries, are inadequate or at best very weak tests of rational voting models. 


\section{Appendix}

\section{VII.1 Proof of Lemma 1}

Let $u_{\theta}$ for $\theta=A, B$ be the expected utility of an uninformed swing voter of voting for policy $\theta$. To evaluate $u_{A}-u_{B}$ there are only three relevant events: $P_{0}$, the event when there is a tie among the other voters between $A$ and $B$; and $P_{\theta}$ for $\theta=A, B$, which is the event in which policy $\theta$ is losing by one vote. The expected net utility of voting for $A$ rather than $B$ conditional on event $P_{i}$ is

$$
E\left(u_{A}-u_{B} \mid P_{i}\right)=\left\{\begin{array}{lc}
\operatorname{Pr}\left(A \mid P_{i}\right)-0.5 & i=A, B \\
2 \operatorname{Pr}\left(A \mid P_{i}\right)-1 & i=0
\end{array}\right.
$$

We can therefore write:

$$
\begin{aligned}
u_{A}-u_{B} & =\left[\pi \operatorname{Pr}\left(P_{0} \mid A\right)-(1-\pi) \operatorname{Pr}\left(P_{0} \mid B\right)\right]+\frac{1}{2} \sum_{i=A, B} \operatorname{Pr}\left(P_{i}\right)\left(2 \operatorname{Pr}\left(A \mid P_{i}\right)-1\right) \\
& =\left[\pi \operatorname{Pr}\left(P_{0} \mid A\right)-(1-\pi) \operatorname{Pr}\left(P_{0} \mid B\right)\right]+\frac{1}{2}\left[\begin{array}{c}
\pi \operatorname{Pr}\left(P_{B} \mid A\right)-(1-\pi) \operatorname{Pr}\left(P_{B} \mid B\right) \\
+\pi \operatorname{Pr}\left(P_{A} \mid A\right)-(1-\pi) \operatorname{Pr}\left(P_{A} \mid B\right)^{(3)}
\end{array}\right. \\
& =\left(\Lambda_{0}+\frac{1}{2} \Lambda_{1}\right)
\end{aligned}
$$

where $\Lambda_{0}=\left[\pi \operatorname{Pr}\left(P_{0} \mid A\right)-(1-\pi) \operatorname{Pr}\left(P_{0} \mid B\right)\right]$ and

$$
\Lambda_{1}=\pi \operatorname{Pr}\left(P_{B} \mid A\right)-(1-\pi) \operatorname{Pr}\left(P_{B} \mid B\right)+\pi \operatorname{Pr}\left(P_{A} \mid A\right)-(1-\pi) \operatorname{Pr}\left(P_{A} \mid B\right)
$$

Consider $\Lambda_{1}$ first. Since $n$ is odd, we can write:

$$
\begin{aligned}
\Lambda_{1}= & \sum_{j=0}^{\frac{n-3}{2}}\left(\frac{(n-1) !}{\left(\frac{n-(2 j+1)}{2}\right) !\left(\frac{n-2-(2 j+1)}{2}\right) !(2 j+1) !}\right)\left[(1-p) \sigma_{\phi}\right]^{(2 j+1)} \\
& \cdot\left[p+(1-p)\left(1-\sigma_{\phi}\right)\right] \cdot\left\{\begin{array}{c}
\pi\left[\begin{array}{c}
p(1-p) \sigma_{B} \\
+(1-p)^{2} \sigma_{A} \sigma_{B}
\end{array}\right]^{\frac{n-(2 j+1)-2}{2}} \\
-(1-\pi)\left[\begin{array}{c}
p(1-p) \sigma_{A} \\
+(1-p)^{2} \sigma_{A} \sigma_{B}
\end{array}\right]^{\frac{n-(2 j+1)-2}{2}}
\end{array}\right\}
\end{aligned}
$$

Consider now $\Lambda_{0}$. We can write:

$$
\begin{aligned}
\Lambda_{0}= & \sum_{j=0}^{\frac{n-1}{2}}\left(\frac{(n-1) !}{\left(\frac{n-1-2 j}{2}\right) !\left(\frac{n-1-2 j}{2}\right) !(2 j) !}\right)\left[(1-p) \sigma_{\phi}\right]^{2 j} \\
& \cdot\left\{\begin{array}{c}
\pi\left[p(1-p) \sigma_{B}+(1-p)^{2} \sigma_{A} \sigma_{B}\right]^{\frac{n-1-2 j}{2}} \\
-(1-\pi)\left[p(1-p) \sigma_{A}+(1-p)^{2} \sigma_{A} \sigma_{B}\right]^{\frac{n-1-2 j}{2}}
\end{array}\right\}>0
\end{aligned}
$$


Assume by contradiction that $\sigma_{B}>\sigma_{A}$. Since $\pi \geq \frac{1}{2}$, we conclude that $\Lambda_{1}>0$ and $\Lambda_{0}>0$. So $u_{A}-u_{B}>0$, which implies that $\sigma_{B} \leq \sigma_{A}$, a contradiction. We conclude that $\sigma_{A} \geq \sigma_{B}$. When $\pi=\frac{1}{2}$ we can make the symmetric argument and prove $\sigma_{B} \geq \sigma_{A}$. Hence $\pi=\frac{1}{2} \Rightarrow \sigma_{B}=\sigma_{A}$.

\section{VII.2 Proof of Proposition 1}

If $\sigma_{B}>0$, then the voter must be indifferent between the two alternatives since $\sigma_{A} \geq \sigma_{B}$ $\forall \pi \geq \frac{1}{2}$. Assume this is the case, then:

$$
\begin{aligned}
0= & u_{A}-u_{B}=\operatorname{Pr}\left[P_{0}\right] \cdot\left[2 \operatorname{Pr}\left(A \mid P_{0}\right)-1\right] \\
& +\frac{1}{2} \operatorname{Pr}\left[P_{A}\right] \cdot\left[2 \operatorname{Pr}\left(A \mid P_{A}\right)-1\right] v+\frac{1}{2} \operatorname{Pr}\left[P_{B}\right] \cdot\left[2 \operatorname{Pr}\left(A \mid P_{B}\right)-1\right]
\end{aligned}
$$

This equation implies:

$$
\begin{aligned}
& {\left[\pi \operatorname{Pr}\left(P_{0} \mid A\right)-(1-\pi) \operatorname{Pr}\left(P_{0} \mid B\right)\right] } \\
= & \frac{1}{2}\left[(1-\pi) \operatorname{Pr}\left(P_{B} \mid B\right)-\pi \operatorname{Pr}\left(P_{B} \mid A\right)\right]+\frac{1}{2}\left[(1-\pi) \operatorname{Pr}\left(P_{A} \mid B\right)+\pi \operatorname{Pr}\left(P_{A} \mid A\right)\right]
\end{aligned}
$$

Moreover, we have:

$$
u_{A}-u_{\phi}=\frac{1}{2}\left[\pi \operatorname{Pr}\left(P_{0} \mid A\right)-(1-\pi) \operatorname{Pr}\left(P_{0} \mid B\right)\right]+\frac{1}{2}\left[\pi \operatorname{Pr}\left(P_{A} \mid A\right)-(1-\pi) \operatorname{Pr}\left(P_{A} \mid B\right)\right]
$$

Substituting (5) in (6), we obtain:

$$
u_{A}-u_{\phi}=\frac{1}{4} \pi\left[\operatorname{Pr}\left(P_{A} \mid A\right)-\operatorname{Pr}\left(P_{B} \mid A\right)\right]+\frac{1}{4}(1-\pi)\left[\operatorname{Pr}\left(P_{B} \mid B\right)-\operatorname{Pr}\left(P_{A} \mid B\right)\right]
$$

We can compute:

$$
\begin{aligned}
& \operatorname{Pr}\left(P_{B} \mid B\right)=\sum_{j=0}^{\frac{n-3}{2}} \Phi(j){\frac{\left[p(1-p) \sigma_{A}+(1-p)^{2} \sigma_{A} \sigma_{B}\right]}{p+(1-p) \sigma_{B}}}^{\frac{n-(2 j+1)}{2}} \\
& \operatorname{Pr}\left(P_{B} \mid A\right)=\sum_{j=0}^{\frac{n-3}{2}} \Phi(j){\frac{\left[p(1-p) \sigma_{B}+(1-p)^{2} \sigma_{A} \sigma_{B}\right]}{(1-p) \sigma_{B}}}^{\frac{n-(2 j+1)}{2}}
\end{aligned}
$$

and

$$
\begin{aligned}
& \operatorname{Pr}\left(P_{A} \mid A\right)=\sum_{j=0}^{\frac{n-3}{2}} \Phi(j) \frac{\left[p(1-p) \sigma_{B}+(1-p)^{2} \sigma_{A} \sigma_{B}\right]}{p+(1-p) \sigma_{A}} \\
& \operatorname{Pr}\left(P_{A} \mid B\right)=\sum_{j=0}^{\frac{n-3}{2}} \Phi(j) \frac{\left[p(1-p) \sigma_{A}+(1-p)^{2} \sigma_{A} \sigma_{B}\right]}{(1-p) \sigma_{A}}
\end{aligned}
$$


where: $\Phi(j)=\left(\frac{(n-1) !}{\left(\frac{n-(2 j+1)}{2}\right) !\left(\frac{n-2-(2 j+1)}{2}\right) !(2 j+1) !}\right)\left[(1-p) \sigma_{\phi}\right]^{(2 j+1)}$. From these expressions is evident that $\left[\operatorname{Pr}\left(P_{A} \mid A\right)-\operatorname{Pr}\left(P_{B} \mid A\right)\right]<0$ and $\left[\operatorname{Pr}\left(P_{B} \mid B\right)-\operatorname{Pr}\left(P_{A} \mid B\right)\right]<0$, which implies that $u_{A}-u_{\phi}<0$, and therefore $\sigma_{A}=0$. So $\sigma_{B} \leq \sigma_{A}=0$, a contradiction. Using Lemma 1 , we conclude that $\pi=\frac{1}{2}$ implies $\sigma_{A}=\sigma_{B}=0$; and $\pi>\frac{1}{2} \operatorname{implies} \sigma_{A} \geq \sigma_{B}=0$, as stated in the proposition.

\section{VII.3 Proof of Lemma 2}

Assume by contradiction that $m>0$ and $\sigma_{A} \geq \sigma_{B}$. The expected utility of voting for $A$ net of the utility of voting for $B$ can be expressed as in (2) and 3 . In this case:

$$
\begin{aligned}
\Lambda_{1}= & \sum_{j=0}^{\frac{n-3-m}{2}}\left(\frac{(n-1) !}{\left(\frac{n-(2 j+1)-m}{2}\right) !\left(\frac{n-2-(2 j+1)+m}{2}\right) !(2 j+1) !}\right)\left[(1-p) \sigma_{\phi}\right]^{(2 j+1)} \\
& \cdot\left[p+(1-p)\left(1-\sigma_{\phi}\right)\right] \\
& \cdot\left\{\begin{array}{c}
\pi\left[\frac{(1-p) \sigma_{B}}{p+(1-p) \sigma_{A}}\right]^{\frac{m}{2}}\left[p(1-p) \sigma_{B}+(1-p)^{2} \sigma_{A} \sigma_{B}\right]^{\frac{n-(2 j+1)-2}{2}} \\
-(1-\pi)\left[\frac{p+(1-p) \sigma_{B}}{(1-p) \sigma_{A}}\right]^{\frac{m}{2}}\left[p(1-p) \sigma_{A}+(1-p)^{2} \sigma_{A} \sigma_{B}\right]^{\frac{n-(2 j+1)-2}{2}}
\end{array}\right\}
\end{aligned}
$$

Consider now $\Lambda_{0}$. We can write:

$$
\begin{aligned}
\Lambda_{0}= & \sum_{j=0}^{\frac{n-1-m}{2}}\left(\frac{(n-1) !}{\left(\frac{n-1-2 j-m}{2}\right) !\left(\frac{n-1-2 j+m}{2}\right)(2 j) !}\right)\left[(1-p) \sigma_{\phi}\right]^{2 j} \\
& \cdot\left\{\begin{array}{c}
\pi\left[\frac{(1-p) \sigma_{B}}{p+(1-p) \sigma_{A}}\right]^{\frac{m}{2}}\left[p(1-p) \sigma_{B}+(1-p)^{2} \sigma_{A} \sigma_{B}\right]^{\frac{n-2 j-1}{2}} \\
-(1-\pi)\left[\frac{p+(1-p) \sigma_{B}}{(1-p) \sigma_{A}}\right]^{\frac{m}{2}}\left[p(1-p) \sigma_{A}+(1-p)^{2} \sigma_{A} \sigma_{B}\right]^{\frac{n-2 j-1}{2}}
\end{array}\right\}<0
\end{aligned}
$$

Consider first the case in which $\pi=\frac{1}{2}$, and assume by contradiction that $\sigma_{A}>\sigma_{B}$. Since $\frac{(1-p) \sigma(B)}{p+(1-p) \sigma(A)}<\frac{p+(1-p) \sigma(B)}{(1-p) \sigma(A)}$ we have $\Lambda_{0}<0$ and $\Lambda_{1}<0$ : so $<0$, which implies that $\sigma_{B} \geq \sigma_{A}$, a contradiction. Consider now the case in which $\pi>\frac{1}{2}$. There is a $\bar{p}$ such that $\pi\left[\frac{(1-p) \sigma_{B}}{p+(1-p) \sigma_{A}}\right]^{\frac{m}{2}}<(1-\pi)\left[\frac{p+(1-p) \sigma_{B}}{(1-p) \sigma_{A}}\right]^{\frac{m}{2}}$ for any $p>\bar{p}$. Assume by contradiction that $\sigma_{A}>\sigma_{B}$ and $p \geq \bar{p}$. In this case too $\Lambda_{0}<0$ and $\Lambda_{1}<0$ : so again $u_{A}-u_{\phi}<0$, which implies that $\sigma_{B} \geq \sigma_{A}$, a contradiction.

\section{VII.4 Proof of Proposition 2}

Assume that $\sigma_{A}>0$, then since $\sigma_{B} \geq \sigma_{A}$, it must be that $u_{A}-u_{B}=0$. Proceeding as in Proposition 1 we can obtain:

$$
u_{A}-u_{\phi}=\frac{1}{4} \pi\left[\operatorname{Pr}\left(P_{A} \mid A\right)-\operatorname{Pr}\left(P_{B} \mid A\right)\right]+\frac{1}{4}(1-\pi)\left[\operatorname{Pr}\left(P_{B} \mid B\right)-\operatorname{Pr}\left(P_{A} \mid B\right)\right]
$$


We can compute:

$$
\begin{aligned}
\operatorname{Pr}\left(P_{B} \mid B\right) & =\sum_{j=0}^{\frac{n-3}{2}} \Phi(j) \frac{\left[p(1-p) \sigma_{A}+(1-p)^{2} \sigma_{A} \sigma_{B}\right]}{p+(1-p) \sigma_{B}} \\
\operatorname{Pr}\left(P_{B} \mid A\right) & =\sum_{j=0}^{\frac{n-3}{2}} \Phi(j) \frac{\left[p(1-p) \sigma_{B}+(1-p)^{2} \sigma_{A} \sigma_{B}\right]^{\frac{n-(2 j+1)-m}{2}}}{(1-p) \sigma_{B}}
\end{aligned}
$$

and

$$
\begin{aligned}
\operatorname{Pr}\left(P_{A} \mid A\right) & =\sum_{j=0}^{\frac{n-3}{2}} \Phi(j) \frac{\left[p(1-p) \sigma_{B}+(1-p)^{2} \sigma_{A} \sigma_{B}\right]}{p+(1-p) \sigma_{A}} \\
\operatorname{Pr}\left(P_{A} \mid B\right) & =\sum_{j=0}^{\frac{n-3}{2}} \Phi(j) \frac{\left[p(1-p) \sigma_{A}+(1-p)^{2} \sigma_{A} \sigma_{B}\right]}{(1-p) \sigma_{A}}
\end{aligned}
$$

where: $\Phi(j)=\left(\frac{(n-1) !}{\left(\frac{n-(2 j+1)-m}{2}\right) !\left(\frac{n-2-(2 j+1)+m}{2}\right) !(2 j+1) !}\right)((1-p)(1-\sigma))^{(2 j+1)}$. From these expressions is evident that $\left[\operatorname{Pr}\left(P_{A} \mid A\right)-\operatorname{Pr}\left(P_{B} \mid A\right)\right]<0$ and $\left[\operatorname{Pr}\left(P_{A} \mid B\right)-\operatorname{Pr}\left(P_{B} \mid B\right)\right]<0$, which implies that $u_{A}-u_{\phi}<0$ : and therefore $\sigma_{A}=0$, a contradiction.

We now prove that $\sigma_{B}>0$. If this is not the case, the only other possibility is that $\sigma_{B}=\sigma_{A}=0$ : we now show that this is impossible. We can write:

$$
u_{B}-u_{\phi}=\frac{1}{2}(1-\pi) \operatorname{Pr}\left(P_{0} \mid B\right)-\pi \operatorname{Pr}\left(P_{0} \mid A\right)+\frac{1}{2}\left[(1-\pi) \operatorname{Pr}\left(P_{B} \mid B\right)-\pi \operatorname{Pr}\left(P_{B} \mid A\right)\right]
$$

Since when $\sigma_{B}=\sigma_{A}=0$ we have $\operatorname{Pr}\left(P_{0} \mid A\right)=\operatorname{Pr}\left(P_{B} \mid A\right)=0$, and $\operatorname{Pr}\left(P_{0} \mid B\right)>0$, $\operatorname{Pr}\left(P_{B} \mid B\right)$, we have $u_{B}-u_{\phi}>0$, which implies $\sigma_{B}>0$. 


\section{VII.5 Multinomial Probit Estimations of Learning Effects by Session}

Tables A1-A4 summarizes the results of the multinomial logit estimations discussed in sections V.2.1. Each subsession was estimated separately and the standard error was adjusted for clustering by subject in the subsession.

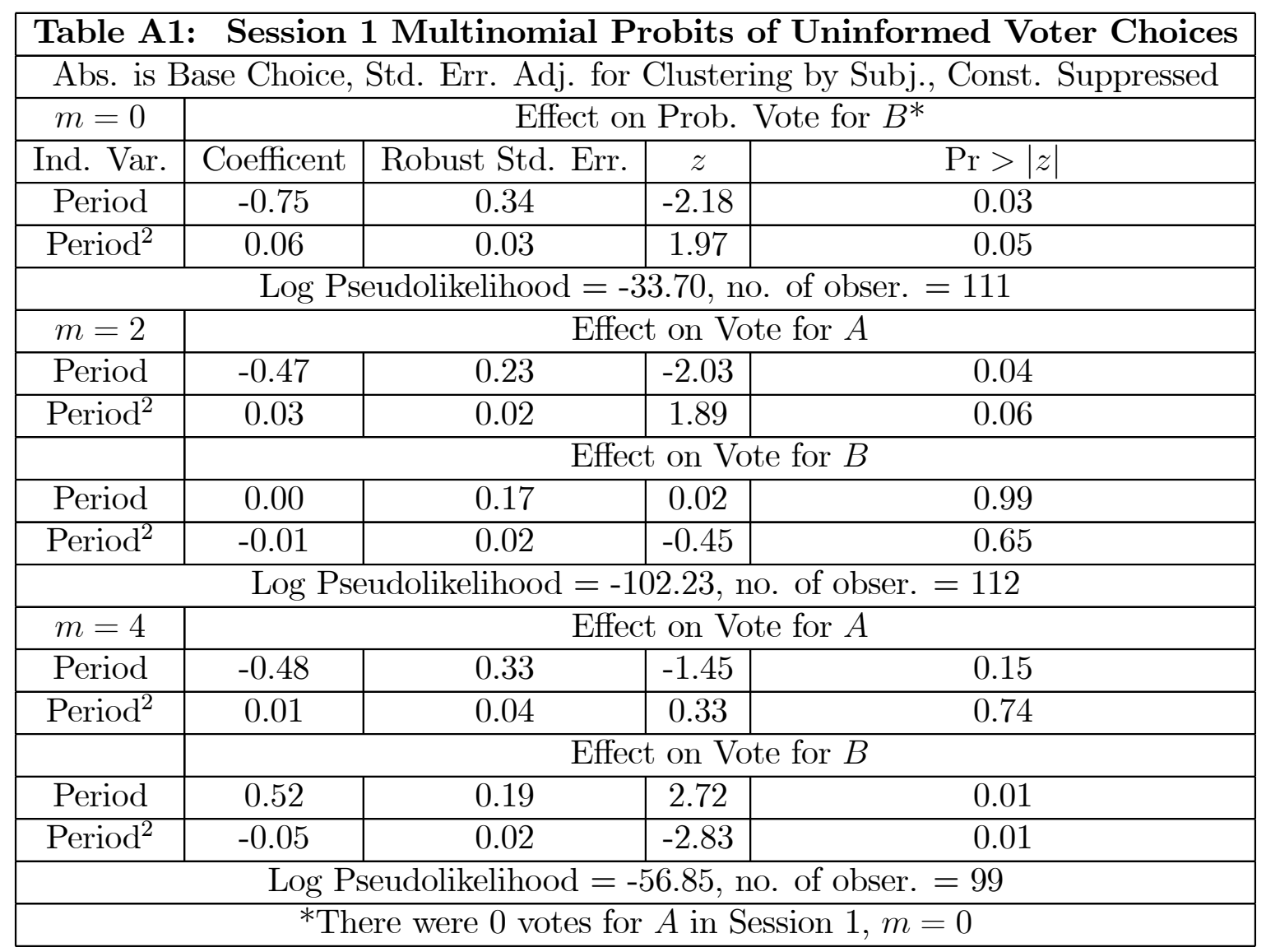




\begin{tabular}{|c|c|c|c|c|}
\hline \multicolumn{5}{|c|}{ Table A2: Session 2 Multinomial Probits of Uninformed Voter Choices } \\
\hline \multicolumn{5}{|c|}{$\begin{array}{l}\text { Abs. is Base Choice, Std. Err. Adj. for Clustering by Subj., Const. Suppressed } \\
m=0\end{array}$} \\
\hline Ind. Var. & Coefficent & Robust Std. Err. & $z$ & $\operatorname{Pr}>|z|$ \\
\hline Period & -1.36 & 0.49 & -2.77 & 0.01 \\
\hline Period $^{2}$ & 0.09 & 0.06 & 1.52 & 0.13 \\
\hline \multicolumn{5}{|c|}{ Effect on Prob. Vote for $B$} \\
\hline Period & -0.76 & 0.30 & -2.55 & 0.01 \\
\hline Period $^{2}$ & 0.06 & 0.02 & 2.64 & 0.01 \\
\hline \multicolumn{5}{|c|}{ Log Pseudolikelihood $=-39.29$, no. of obser. $=106$} \\
\hline$m=2$ & \multicolumn{4}{|c|}{ Effect on Vote for $A$} \\
\hline Period & -0.81 & 0.18 & -4.39 & 0.00 \\
\hline Period $^{2}$ & 0.07 & 0.02 & 4.71 & 0.00 \\
\hline & \multicolumn{4}{|c|}{ Effect on Vote for $B$} \\
\hline Period & -0.00 & 0.14 & -0.03 & 0.98 \\
\hline Period $^{2}$ & 0.00 & 0.01 & 0.12 & 0.91 \\
\hline \multicolumn{5}{|c|}{ Log Pseudolikelihood $=-92.50$, no. of obser. $=109$} \\
\hline$m=4$ & \multicolumn{4}{|c|}{ Effect on Vote for $A$} \\
\hline Period & -0.49 & 0.27 & -1.83 & 0.07 \\
\hline Period $^{2}$ & 0.05 & 0.02 & 2.03 & 0.04 \\
\hline & \multicolumn{4}{|c|}{ Effect on Vote for $B$} \\
\hline Period & 0.36 & 0.21 & 1.71 & 0.09 \\
\hline Period $^{2}$ & -0.02 & 0.02 & -1.13 & 0.26 \\
\hline \multicolumn{5}{|c|}{ Log Pseudolikelihood $=-73.76$, no. of obser. $=107$} \\
\hline
\end{tabular}




\begin{tabular}{|c|c|c|c|c|}
\hline$\frac{\text { Table A }}{\text { Abst }}$ & $\frac{: \text { Session }}{\text { ntion is Bas }}$ & Multinomial P & $\frac{\text { obits }}{\text { Adjus }}$ & $\begin{array}{l}\text { ned Voter Cho } \\
\text { ering by Subject }\end{array}$ \\
\hline$m=0$ & & Effect o & Prob. & \\
\hline Ind. Var. & Coefficent & Robust Std. Err. & $z$ & $\operatorname{Pr}>|z|$ \\
\hline Period & -0.23 & 0.19 & -1.19 & 0.23 \\
\hline Period $^{2}$ & 0.01 & 0.02 & 0.94 & 0.35 \\
\hline & & Effect ol & Prob. & \\
\hline Period & -0.72 & 0.30 & -2.36 & 0.02 \\
\hline Period $^{2}$ & 0.05 & 0.03 & 1.96 & 0.05 \\
\hline & $\log \mathrm{P}$ & eudolikelihood = - & $5.50,1$ & $=98$ \\
\hline$m=2$ & & Effec & on $\mathrm{Vc}_{\mathrm{s}}$ & \\
\hline Period & -0.65 & 0.30 & -2.17 & 0.03 \\
\hline Period $^{2}$ & 0.05 & 0.03 & 1.54 & 0.12 \\
\hline & & Effec & on $\mathrm{Vc}$ & \\
\hline Period & -0.24 & 0.14 & -1.70 & 0.09 \\
\hline Period $^{2}$ & 0.03 & 0.02 & 1.66 & 0.10 \\
\hline & $\log \mathrm{P}$ & eudolikelihood $=-$ & $4.80, \mathrm{r}$ & $=98$ \\
\hline$m=4$ & & Effec & on $\mathrm{Vc}$ & \\
\hline Period & -0.79 & 0.25 & -3.17 & 0.00 \\
\hline Period $^{2}$ & 0.07 & 0.02 & 3.09 & 0.00 \\
\hline & & Effec & on $\mathrm{Vc}$ & \\
\hline Period & 0.25 & 0.20 & 1.25 & 0.21 \\
\hline Period $^{2}$ & -0.02 & 0.02 & -1.09 & 0.27 \\
\hline & $\log 1$ & udolikelihood $=$ & $8.23,1$ & $=89$ \\
\hline
\end{tabular}




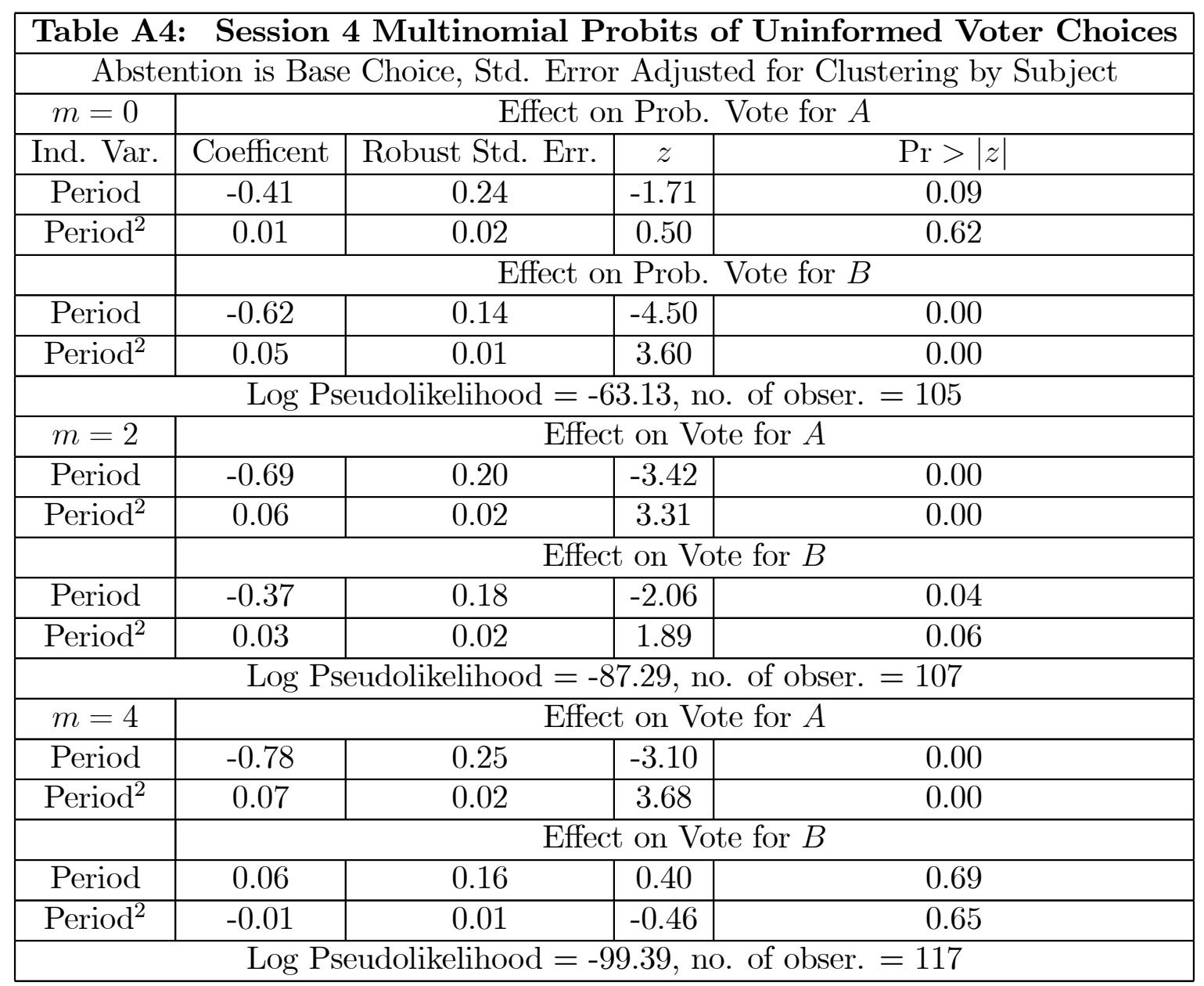

\section{VII.6 Experiment instructions for one of the sessions}

Thank you for agreeing to participate in this experiment. This is an experiment in group decision making. During the experiment we require your complete, undistracted attention and ask that you follow instructions carefully. Please turn off your cell phones. Do not open other applications on your computer, chat with other students, or engage in other distracting activities, such as reading books, doing homework, etc. You will be paid for your participation in cash, at the end of the experiment. Different participants may earn different amounts. What you earn depends partly on your decisions, partly on the decisions of others, and partly on chance. The entire experiment will take place through computer terminals. It is important that you not talk or in any way try to communicate with other participants during the experiments.

The experiment you are participating in is a group decision making experiment, where you will be making decisions in committees. We will start with a brief instruction period. During the instruction period, you will be given a complete description of the experiment 
and will be shown how to use the computers. If you have any questions during the instruction period, please raise your hand and your question will be answered out loud so everyone can hear. If you have any questions after the experiment has begun, raise your hand, and an experimenter will come and assist you. The practice session will be followed by the paid session. At the end of the paid session, you will be paid the sum of what you have earned, plus a show-up fee of $\$ 10.00$. Everyone will be paid in private and you are under no obligation to tell others how much you earned. Your earnings during the experiment are denominated in FRANCS. Your DOLLAR earnings are determined by multiplying your earnings in FRANCS by a conversion rate. For this experiment the conversion rate is 0.01 , meaning that 100 FRANCS equal 1 DOLLAR. The computer keeps a record of the payments, but you are also asked to keep track of your earnings on a record sheet.

For the entire experiment, there will be a monitor, who will be chosen from one of the participants in this room. The monitor will assist in running the experiment by rolling a die and generating random numbers for use in the experiment and will be paid a fixed amount (\$20.00) for the experiment. [Select monitor] The monitor is the participant who is seated in front of computer \#XX. Please go to Computer \# 21. Please continue to pay attention to the Instructions as they are also relevant to you. If you have any questions, please ask. If you should have questions once the experiment has started, please ask the assistant sitting next to you. We will now begin a brief instruction period followed by a practice session. You will not be paid for the practice session. After the practice session, there will be a short comprehension quiz, and all questions must be answered correctly before continuing to the paid session.

Part 1

This experiment has 3 parts. The first part of the experiment will take place over a sequence of 10 matches. We begin the first match by dividing you into 2 committees of seven members each. Each of you is assigned to exactly one of these committees. You are not told the identity of the other members of your committee.

Your committee will make one of two decisions. The decision is simply a choice between one of two "jars", the Red Jar or the Yellow Jar. Committees make decisions by voting. Whichever jar receives more votes is the committee's decision, and ties are broken randomly. At the beginning of the match, the monitor secretly rolls a 10-sided die to determine which of the two jars is the correct jar for your committee, and enters this information into the master computer. If the die rolled by the monitor comes up $1,2,3$, 4 or 5 then the Red Jar is the correct jar for your committee; if the die comes up 6, 7, 8 or 9, the Yellow Jar is the correct jar for your committee. If the die comes up a 10, then it will be rolled again until one of the first 9 numbers comes up. Therefore, in each match 
there is a 5 out of 9 chance your committee's correct jar is Red and a 4 out of 9 chance it is Yellow. The die is rolled separately for each committee, and separately for each match. The color of your committee's jar is then recorded in the computer. You will not be told which jar is the correct decision until after all the members in your committee have voted. Before voting, each of you receive a piece of information that may or may not help you decide which is the correct jar. We will describe this information in a moment.

Payoffs are determined as follows. If your committee decision is the correct jar, everyone in your committee receives a high payoff equal to 80 francs. If your committee decision is not the correct jar, everyone in the committee receives a low payoff equal to 5 francs.

After receiving this piece of information, you must either vote of one of the two jars or abstain. Ties (0-0, 1-1, 2-2, 3-3) are broken randomly. So, for example if three of the seven members of the committee voted for yellow jar, three voted for red jar, and 1 member abstained, then the total vote would be $3-3$, which is a tie, and the tie would be broken randomly. After everyone in your committee has made their decisions to either vote or abstain, you are told the group decision, exactly what the total votes were, and the correct jar is revealed to you. If your committee's group decision is equal to the Correct jar, each member of your committee earns 80 francs. If your committee's group decision is incorrect, each member of your committee earns 5 francs. The other committees in the room face similar tasks, but the correct decision may be different for different committees. Remember that committees are completely independent, and they act independently.

After the first match is completed, we proceed to the second match and the process repeats itself. This will continue for a total of 10 matches. After 10 matches, the first part of the experiment will be complete and we will read you instructions for the second part.

From now on the experiment will take place through computer terminals only, except for the roll of the die performed by the monitor.

We will now begin a Practice session and go through one practice match. During the practice match, please do not hit any keys until you are asked to, and when you are instructed to enter information, please do exactly as asked. Again, you are not paid for this practice match.

\section{[AUTHENTICATE CLIENTS]}

Please double click on the icon on your desktop that says s-v-c. When the computer prompts you for your name, type your First and Last name. Then click SUBMIT and wait for further instructions.

[SCREEN 1]

You now see the first screen of the experiment on your computer. It should look similar to this screen. [POINT TO PPT SLIDE DISPLAYED ON SCREEN IN FRONT 
OF ROOM] Please note that the screen exhibited up front is not necessarily exactly identical to the screen exhibited on your computer at this time. All the slides we display in front are just to illustrate.

At the top left of the screen, you see your subject ID. [POINT and mention that your subject number may be different] Please record that on your record sheet now. You have been assigned by the computer to a group of 7 subjects. This committee assignment will change after each match.

On the upper right of your screen there are pictures of two jars, each containing exactly 12 balls. The Red Jar contains 3 Red balls and 9 White balls. The Yellow Jar contains 3 Yellow balls, and 9 White balls.

The monitor will now roll a die, to determine a jar for each committee for this match and will enter this information into the computer. The Jar for a committee represents that committee's correct decision. The die is rolled separately for each committee. As a result, either Jar may be the correct Jar for each committee.

As I said before, different committees may have been assigned different Jars. You will not be told which Jar was assigned to your committee until everyone in your committee has chosen to vote or Abstain. Before you make your choice, each of you is allowed to see a small piece of information that may or may not help you determine which jar was assigned to your group. Please wait... we will explain this shortly.

[PUT UP TABLE WITH PAYOFFS]

If you look at the screen in the front of the room, it shows how your payoff is determined. If your committee's decision matches the committee's actual Jar, you earn 80 francs for the match and you earn 5 francs if the group decision does not match the actual Jar. [GO THROUGH EACH LINE ON THE TABLE]

[SCREEN 2]

After the monitor has rolled the die for each committee to determine that committee's correct jar, and the information has been entered into the master computer, you will see this screen. You now see only one jar on your screen, but the colors of the balls are hidden so at this point you cannot tell which jar it is. This jar is your committee's correct jar. If it is a red jar, then there are 3 red balls and 9 white balls; if it is a yellow jar, then there are 3 yellow balls and 9 white balls.

(Emphasize and repeat later) Please note that the balls have been randomly shuffled on each of your screens by the computer so there is no way to guess which color ball is in which location and you cannot tell which Jar was assigned to your committee.

You will now be allowed to see the color of exactly one of the balls in your committee's jar. To do so, now please use the mouse to move your cursor to whichever ball you want to look at and click once. 


\section{[SHOW SCREEN 3]}

We call this ball "your sample". It is your piece of private information. The other members of your committee are also choosing balls in a similar way, although the locations of their balls were shuffled differently for each subject. Therefore, different members of the same committee may be clicking on different color balls even from the same jar. However, if the jar is the red jar, then only red and white balls are possible, and if the jar is the yellow jar, then only yellow and white balls are possible. The colors of all the other balls remain hidden until the end of the match. Please record the color of your sample on your record sheet ( $\mathrm{R}$ for red or $\mathrm{Y}$ for Yellow or $\mathrm{W}$ for White).

Since the Red Jar has no yellow balls and the Yellow Jar has no red balls, this means that if you picked a red ball, your committee's jar must be the Red Jar, and if you picked a yellow ball, your committee's jar must be the Yellow Jar. Also since 9 of the 12 balls in each jar are white, drawing a white ball gives you no useful information about your committee's Jar.

We now move to the voting stage.

At this point you will have an opportunity to either vote for the Red Jar, vote for the Yellow Jar, or Abstain. Since this is a practice match, we are not going to let you choose, but instead ask that you vote according to your id number. If your ID number is between 0 and 5 (7 IF 21 SUBJECTS), vote for Red. If your ID number is between 6 and 10 (8 AND 14 IF 21 SUBJECTS), vote for Yellow. If your ID number is between 11 and 14, Abstain. Of course, during the paid matches, you will be making your own decisions.

Once everyone has voted or abstained, you are told the committee decision and your committee's jar is revealed to you on this screen.

\section{[SHOW SCREEN 4]}

This final screen also displays the correct jar for your committee, your committee's decision, how many votes each Jar received and how many voters in your committee abstained. Also, please note that at the end of the match the colors of all the balls in your jar are revealed to you. This marks the end of the match.

Now we are ready for the short comprehension quiz. Everyone must answer all the questions correctly before we go to the paid matches. Also, during the quiz, you must answer all the questions on Page 1 of the quiz to proceed to Page 2 and 3. If you answer a question incorrectly, you will be asked to correct it. Please raise your hand if you have any questions during the quiz, and we will come to your desk and answer your question in private.

\section{[SHOW SCREEN 5]}

Your total payoff is displayed. Please click on the "OK" button to finish the match. [SHOW SCREEN 6] 
The table with columns in the bottom of your screen is the History panel and summarizes all of this important information.

[AS YOU READ THE FOLLOWING PARAGRAPH, POINT TO RELEVANT COLUMNS ON THE SCREEN IN FRONT]

COLUMN ONE indicates the match number, COLUMN TWO indicates your sample color, COLUMN THREE shows your vote, COLUMN four provides a summary of the votes: (Red Jar- Yellow Jar -Abstention), COLUMN FIVE shows your committee's decision, COLUMN SIX shows the what the actual jar was, and COLUMN SEVEN shows your earnings (which are not listed here because this was a practice session).

Now, please make sure you have recorded all the information for this practice match on your record sheet. You must record this after each match.

In summary, please remember the following important things. The committee decision is made by plurality rule. Whichever jar receives more votes is the committee decision, with ties broken randomly by the computer. Committee decisions are summarized in the text in the upper left panel of your screen (POINT), and are also summarized in the history screen at the bottom in column five (POINT). As the experiment proceeds the history screen will gradually list information about all the previous committees you were in.

[DISPLAY NEW SLIDE WITH SUMMARY INFORMATION and summarize it by pointing]

[START GAME]

Are there any questions before we begin with the paid session?

[WAIT FOR QUESTIONS]

We will now begin with the 10 paid matches of the first part of the experiment, remember there are 3 parts in this experiment. We will explain the instructions for part 2 after part 1 is finished and will read the instructions for part 3 after part 2 is finished. Please pull out your dividers for the paid session of the experiment. If there are any problems or questions from this point on, raise your hand and an experimenter will come and assist you.

[DO NOT USE AUTO ADVANCE MATCHES. AFTER MATCH 10 (server) READ THE FOLLOWING NEW INSTRUCTIONS]

Part 2

This completes part 1. Part 2 is almost exactly the same as part 1, with one exception. The computer plays the role of two additional members of your committee. Those two computerized members of your committee always vote for the red jar no matter what. As before, your committee's decision is made by plurality rule. Whichever jar receives more votes, including the two red jar votes from the computer, is your committee's decision. 
There will be 10 matches in part 2 .

[DISPLAY NEW SLIDE WITH SUMMARY INFORMATION, AND POINT OUT THE NEW BULLET ITEM ABOUT THE 2 COMPUTER VOTES]

We now begin part 2.

[START MATCH 11 (server). AFTER MATCH 20 (server), READ THE FOLLOWING INSTRUCTIONS]

[DO NOT USE AUTO ADVANCE MATCHES. AFTER MATCH 21, READ THE FOLLOWING NEW INSTRUCTIONS]

Part 3

This completes part 2. Part 3 is almost exactly the same as part 2, with one exception. There will now be 4 computerized votes in each committee. As in the previous part, all 4 of these computerized votes are cast for the Red Jar in all committees and in all matches. There will be 10 matches in part 3 .

[DISPLAY NEW SLIDE WITH SUMMARY INFORMATION, AND POINT OUT THE NEW BULLET ITEM ABOUT THE 4 COMPUTER VOTES]

We now begin part 3 .

[START MATCH 21 (server). AFTER MATCH 30 (server), READ THE FOLLOWING INSTRUCTIONS]

This completes part 3. Please make sure to record your total payoffs on your record sheet, including your show-up fee of $\$ 10.00$. Please remain in your seat until your ID number is called and leave the dividers as they are. Do not talk or socialize with the other participants or play with the computers. We will now pay each of you in private in the next room in the order of your ID numbers. Please take all belongings with you when you leave to receive payment. You are under no obligation to reveal your earnings to the other players. Thank you for your participation. 


\section{References}

[1] Austen-Smith, David and Jeffrey Banks, 1996. Information Aggregation, Rationality, and the Condorcet Jury Theorem. American Political Science Review. 90, pp. 34-45.

[2] Battaglini, Marco. 2005. Sequential Voting with Abstention. Games and Economic Behavior, 51 (2), pp. 445-63.

[3] Battaglini, Marco, Rebecca Morton, and Thomas Palfrey. 2005. Efficiency, Equity, and Timing in Voting Mechanisms. Working Paper. Center for the Study of Democratic Politics. Princeton University.

[4] Cason, Timothy and V.-L. Mui, 2005. Uncertainty and resistance to reform in laboratory participation games. European Journal of Political Economy. In Press.

[5] Crain, W. Mark, Donald Leavens, and Lynn Abbot. 1987. Voting and Not Voting at the Same Time. Public Choice, 53, pp. 221-29.

[6] Coate, Stephen and Michael Conlin. 2004. A Group Rule-Utilitarian Approach to Voter Turnout: Theory and Evidence," American Economic Review. 94(5), pp. 14761504 .

[7] Coate, Stephen, Michael Conlin and Andrea Moro, 2006. The Performance of the Pivotal-Voter Model in Small-Scale Elections: Evidence from Texas Liquor Referenda. Working Paper. Cornell University.

[8] Coupe, Thomas and Abdul Noury. 2004. Choosing not to choose: on the link between information and abstention, Economics Letters 84, pp. 261-65.

[9] Feddersen, Timothy, 2004. Rational Choice Theory and the Paradox of Not Voting. Journal of Economic Perspectives. 18(1). 99-112.

[10] Feddersen, Timothy and Pesendorfer Wolfgang, 1996. The Swing Voter's Curse, American Economic Review. 86(3), pp. 404-24.

[11] Feddersen, Timothy and Pesendorfer Wolfgang, 1997. Voting Behavior and Information Aggregation in Elections with Private Information. Econometrica. 65, pp. 1029-58.

[12] Feddersen, Timothy and Pesendorfer Wolfgang, 1999. Absetention in Elections with Asymmetric Information and Diverse Preferences. American Political Science Review. 93(2), pp. 381-98. 
[13] Filer, John, Lawrence Kenny, and Rebecca Morton. 1993. "Redistribution, Income, and Voting." American Journal of Political Science, 37, pp. 63-87.

[14] Gentzkow, Matthew. 2005. Television and Turnout. Working paper. University of Chicago Business School.

[15] Grofman, Brenard. 1993. Is Turnout the Paradox that Ate Rational Choice Theory? in Information, Participation, and Choice (ed. B. Grofman), University of Michigan Press: Ann Arbor.

[16] Grosser, Jens, Tamar Kugler and Arthur Schram. 2005. Preference Uncertainty, Voter Participation and Electoral Efficiency: An Experimental Study. Working Paper, University of Cologne.

[17] Guarnaschelli, Serena, Richard McKelvey, and Thomas Palfrey, 2000, An Experimental Study of Jury Decision Rules, American Political Science Review, 94(2), pp. $407-23$.

[18] Hansen, Stephen, Thomas Palfrey, and Howard Rosenthal. 1987. The Downsian Model of Electoral Participation: Formal Theory and Empirical Analysis of the Constituency Size Effect. Public Choice. 52: 15-33.

[19] Kagel, John and Dan Levin. 2002. Common Value Auctions and the Winner's Curse, Princeton University Press: Princeton.

[20] Klein, David and Lawrence Baum. 2001. Ballot Information and Voting Decisions in Judicial Elections. Political Research Quarterly, 54(4), pp. 709-28.

[21] Lassen, David, 2005. The Effect of Information on Voter Turnout: Evidence from a Natural Experiment, American Journal of Political Science, 49(1), pp. 103-18.

[22] Ledyard, John, 1984, The Pure Theory of Large Two-Candidate Elections, Public Choice, 44, pp. 7-41.

[23] Levine, David and Thomas Palfrey, 2007. The Paradox of Voter Participation: An Experimental Study American Political Science Review. in press.

[24] Matsusaka, John, 1995. Explaining Voter Turnout Patterns: An Information Theory. Public Choice, 84, pp. 91-117.

[25] Matsusaka, John and Filip Palda, 1999. Voter Turnout: How Much Can We Explain? Public Choice. 98 pp. 431-46. 
[26] McDermott, Monika, 2005. Candidate Occupations and Voter Information Shortcuts. The Journal of Politics, 67,(1), pp. 201-19.

[27] Noury, Abdul, 2003. Abstention in daylight: Strategic calculus of voting in the European Parliament. Public Choice 212: 179-211, 2004.

[28] Palfrey Thomas and Keith Poole, 1987. The Relationship between Information, Ideology, and Voting Behavior, American Journal of Political Science, 31(3), pp. 511-30.

[29] Palfrey Thomas and Rosenthal Howard, 1983. A Strategic Calculus of Voting. Public Choice. 41, pp. 7-53.

[30] Palfrey Thomas and Rosenthal Howard, 1985. Voting Participation and Strategic Uncertainty. American Political Science Review. 79, pp. 62-78.

[31] Shachar, Ron and Barry Nalebuff, 1999. Follow the Leader: Theory and Evidence on Political Participation. American Economic Review. 89(3), pp. 525-47.

[32] Schram, Arthur and Joop Sonnemans, 1996. Voter Turnout as a Participation Game: An Experimental Investigation, International Journal of Game Theory. 25, pp. 385406.

[33] Thaler, Richard, 1991. The Winner's Curse: Paradoxes and Anomalies of Economic Life, New York: Free Press.

[34] Wattenberg, Martin, Ian McAllister, and Anthony Salvanto. 2000. "How Voting is Like an SAT Test: An Analysis of American Voter Rolloff," American Politics Quarterly, 28(2), pp. 234-50.

[35] Wooldridge, Jeffrey, 2002. Econometric Analysis of Panel and Cross-Sectional Data, Cambridge, MA: MIT Press. 